\title{
IDENTIDAD TAXONÓMICA DE LOS 'TALAS': ANÁLISIS MORFOLÓgICO DE Celtis tala y Celtis pallida (Celtidaceae)
}

\author{
JORGELINA ASMUS ${ }^{1,2^{*}}$, DÉBORA CHAMORRO ${ }^{1,2}$, VIRGINIA Y. MOGNI ${ }^{1,2}$, LUIS J. OAKLEY ${ }^{1,3}$ \\ y DARIÉN E. PRADO ${ }^{1,2}$
}

\begin{abstract}
Summary: Taxonomic Identity of the 'talas': Morphological analysis of Celtis tala and Celtis pallida (Celtidaceae). The genus Celtis (Celtidaceae) comprises around 70 temperate to tropical woody taxa . In Argentina there appear four species, all of them belonging in the subgenus Mertensia Planch., whose inter and intraspecific morphological variability and similarity has generated widespread taxonomic confusions. One of the most emblematic cases is that of $C$. ehrenbergiana (Klotzsch) Liebm., considered a very ample taxon encompassing both $C$. pallida Torr. and $C$. tala Gillies ex Planch. Given that both latter entities are clearly distinguishable in the field, a morphological and taxonomic revision was performed. After extensive sampling, a detailed morphological study and through a Principal Components and Conglomerates Analysis, it was concluded that what is considered as C. ehrenbergiana in Argentina, actually involves three entities: C. tala, C. pallida var. pallida and C. pallida var. discolor Hunz. \& Dottori, and the rehabilitation of those taxa is proposed. The Variance and Similarity Analysis results support significant differences ( $p$-value $<0.05$ ) between groups. The following relevant taxonomical characters were established: habit of the individual, bark pattern, pubescence of leaf blades, nerves and petioles, stipular spines/spiny branches, domacia aspect and abundance. Besides, some C. pallida specimens are morphologically intermediate between both varieties, and therefore their proper identity will be clarified through the use of molecular tools.
\end{abstract}

Key words: Celtis, taxonomic revision, morphological study, Chaco, Espinal.

Resumen: El género Celtis L. (Celtidaceae) comprende unos 70 taxones de árboles o arbustos de regiones templadas y tropicales. En la Argentina habitan cuatro especies, todas pertenecientes al subgénero Mertensia Planch., cuya similitud y variabilidad inter e intraespecíficas han generado confusiones taxonómicas dentro del grupo. Un caso emblemático es el de C. pallida Torr. y C. tala Gillies ex Planch., considerados sinónimos de C. ehrenbergiana (Klotzsch) Liebm. Como estas entidades son claramente diferenciables a campo, se realizó la revisión taxonómica de dichos taxones. Tras un extenso muestreo, un estudio morfológico detallado y a través de un Análisis de Componentes Principales y de Conglomerados, se concluyó que lo considerado en Argentina como C. ehrenbergiana, abarca tres entidades: C. tala, C. pallida var. pallida y C. pallida var. discolor Hunz. \& Dottori, y se propone la rehabilitación de dichos taxones. Asimismo, los resultados de los Análisis de la Varianza y de Similitud corroboran diferencias significativas ( $p$-valor $<0.05$ ) entre grupos. Se establecieron como caracteres de mayor importancia taxonómica: porte de los individuos, textura de corteza, pilosidad de láminas, nervaduras y pecíolos, espinas estipulares/ramas espinosas, abundancia y aspecto de domacios. Además, algunos especímenes de $C$. pallida son morfológicamente intermedios entre ambas variedades, por lo cual su identidad será esclarecida por medio del uso de herramientas moleculares.

Palabras clave: Celtis, revisión taxonómica, estudio morfológico, Chaco, Espinal.

\footnotetext{
${ }^{1}$ Botánica, Facultad de Ciencias Agrarias, Universidad Nacional de Rosario, C.C. №14, 2125 Zavalla, Argentina.

2 Instituto de Investigaciones en Ciencias Agrarias, IICAR CONICET-UNR, 2125 Zavalla, Argentina.

${ }^{3}$ Red List Authority Coordinator for the Temperate South American Plant Specialist Groups -International Union for Conservation of Nature (IUCN).

*jorgelina.asmus@gmail.com
} 


\section{INTRODUCCIÓN}

El género Celtis L. (Celtidaceae) posee unos 70 taxones distribuidos en regiones templadas y tropicales de ambos hemisferios (Sattarian, 2006). Comprende árboles o arbustos generalmente espinosos, muchas veces apoyantes, monoicos o polígamo-monoicos. Tienen hojas alternas, simples, típicamente trinervadas, con margen entero, dentado o aserrado, y frecuentemente con domacios entre las nervaduras principales del envés de la lámina; inflorescencias en cimas paucifloras breves, con flores estaminadas en la base y perfectas en el ápice. Las flores son de color verdoso-amarillentas, $\mathrm{y}$ tanto las masculinas como las hermafroditas poseen cinco estambres opositépalos. El gineceo de las flores masculinas resulta abortivo y el estilo de las flores perfectas sésil o brevistilado (Dottori \& Hunziker, 1994). El fruto consiste en una drupa elipsoide, con pireno calcificado, de superficie rugosa, uniseminado (Sattarian, 2006; Novara, 2009). Según Zuloaga et al. (2008) y en el sitio web de la 'Flora del Cono Sur' (www.darwin.edu. ar ), en Argentina crecen cuatro especies del género: C. brasiliensis (Gardner) Planch., C. chichape (Wedd.) Miq., C. ehrenbergiana (Klotzsch) Liebm. y C. iguanaea (Jacq.) Sarg., todas pertenecientes al subgénero Mertensia Planch. Este subgénero presenta varios problemas taxonómicos no resueltos y los criterios utilizados por los botánicos para diferenciar las especies han cambiado notoriamente a lo largo de los años (Miquel, 1853; Baehni, 1937; Hunziker \& Dottori, 1976; Romanczuk \& del Pero de Martínez, 1978 y Dottori \& Hunziker, 1994).

Uno de los casos más emblemáticos es el de $C$. ehrenbergiana que según Berg \& Dahlberg (2001) es un taxón muy amplio y engloba a $C$. tala Gillies ex Planch. y a $C$. pallida Torr. var. pallida. Sin embargo, según Novara (2009) -quien siguió los criterios de Romanczuk \& del Pero de Martínez (1978) y Dottori \& Hunziker (1994)- estos dos taxones son claramente diferenciables, teniendo en cuenta las siguientes características: $C$. tala es un árbol de 8-10 $\mathrm{m}$ de altura, con espinas geminadas, rectas, áfilas y $C$. pallida es un arbusto de 1-3 m de altura, con espinas caulinares con 1-3 nudos y foliosas (ver Fig. 1 A y B).

Con respecto a $C$. tala, esta especie se distribuye por el norte y centro de Argentina, sur de Brasil y Uruguay (Dottori \& Hunziker, 1994; Brussa \& Grela, 2007). Por otra parte, C. pallida tiene dos

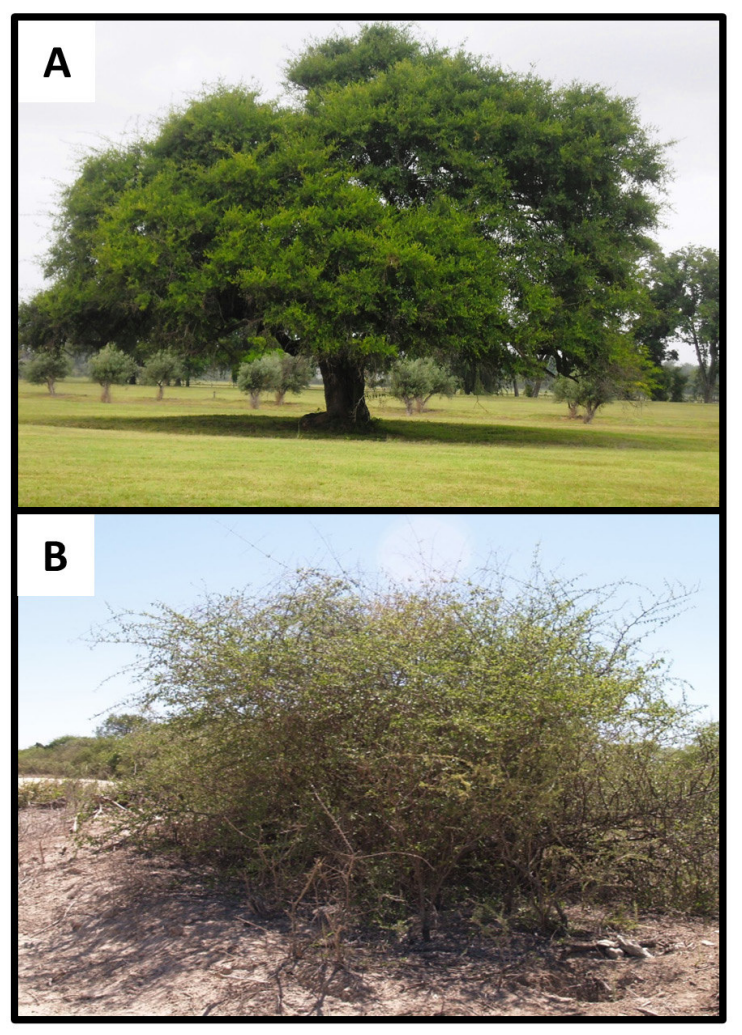

Fig. 1. Aspecto de un ejemplar adulto de A: C. tala y B: C. pallida.

variedades: por un lado la variedad pallida, con área de distribución disyunta, habita en los distritos áridos del sur de EEUU y México, y en Sudamérica en el Chaco de Argentina y Paraguay (Dottori \& Hunziker, 1994; Novara, 2009); y la otra, C. pallida var. discolor Hunz. \& Dottori, restringida al oeste del 'Chaco semiárido' de Argentina y Paraguay. Esta variedad, conocida como "tala negro", "tala pispo" o "tala pispito", había sido considerada en la sinonimia de $C$. chichape por Berg \& Dahlberg (2001), hecho que fue refutado por Oakley \& Prado (2013), a partir de un análisis exhaustivo de los ejemplares tipos.

Asimismo, Henrickson (2010) también planteó dudas sobre los criterios taxonómicos de Berg \& Dahlberg (2001); basándose en los criterios de Hunziker \& Dottori (1976), postuló que $C$. tala y $C$. pallida son dos entidades diferentes y sugiere la realización de estudios moleculares para dilucidar la afinidad entre ambos taxones, destacando la importancia y necesidad de la 


\section{J. Asmus et al. - Identidad taxonómica de Celtis tala y Celtis pallida}

realización de más trabajos de campo. Con respecto a C. ehrenbergiana, Henrickson (2010) afirma, a partir de observaciones sobre los tipos, que este taxón es sinónimo de $C$. iguanaea.

Para esclarecer la circunscripción taxonómica de estas entidades, se realizó una detallada revisión sistemática y morfológica y viajes de campo extensos con el fin de reconocer los taxones estudiados en su hábitat y buscar potenciales ejemplares intermedios. En base a los resultados obtenidos se propone la rehabilitación de los taxones $C$. tala y $C$. pallida -con sus variedades-, y la generación de una clave eficiente para su adecuada determinación, así como el tratamiento taxonómico correspondiente.

\section{Materiales y Métodos}

Se realizó un extenso viaje de campaña durante los meses de noviembre-diciembre de 2014, el cual abarcó la región centro y noroeste del país, recorriéndose ocho provincias argentinas, de modo de cubrir al máximo posible el área de distribución de ambos taxones. Durante el mismo se colectaron 20 especímenes pre-identificados (sensu Dottori \& Hunziker, 1994) como C. tala y 28 como C. pallida (ver Material Suplementario-1). Se consultó además material preservado en los herbarios CORD, CTES, FCQ, LIL, LP, MCNS, P, SI y UNR, así como fotografías de la base de datos JStor Global Plants (http://plants.jstor.org/) para evaluar ejemplares tipo (ver Material Suplementario-2).

Para el análisis morfológico se analizaron 46 caracteres (ver Material Suplementario-Tabla 1) sobre los especímenes colectados, utilizando calibre digital (Wembley, 0-150 mm), el programa para morfometría tpsDig2 (Rohlf, 2013), y lupa estereoscópica. Previo al análisis estadístico, se transformaron aquellas variables categóricas con $\mathrm{n}$ categorías, en $\mathrm{n}-1$ variables binarias (con valor 0 ó 1, "variables auxiliares o variables dummy") (ver Material Suplementario-Tabla 1). Luego, todos los datos de la matriz fueron estandarizados de manera tal de poner en un pie de igualdad a aquellos valores expresados en diferentes unidades $(\mathrm{mm}, \mathrm{cm}, \mathrm{m}$, frecuencias) para que puedan ser comparables entre sí. Los datos acondicionados se analizaron con Infostat (Di Rienzo et al., 2008) y PAST (Hammer et al., 2001); se realizaron Análisis de Componentes Principales (ACP),
Tabla 1. Variables (y estados) más fuertemente correlacionadas con la CP1 y CP2 en el ACP teniendo en cuenta 42 variables vegetativas, altura y diámetro de los individuos.

\begin{tabular}{|c|c|c|}
\hline Variables (y estados) & $\mathrm{CP} 1$ & $\mathrm{CP} 2$ \\
\hline Tipo de Domacio (Bolsillos pocos pelos) & 0.93 & - \\
\hline Pilosidad Peciolo-Haz (Muy piloso) & -0.93 & - \\
\hline Pilosidad Lámina-Haz (Casi glabro) & 0.92 & - \\
\hline Textura Corteza (Rugosa) & 0.92 & - \\
\hline Textura Corteza (Lisa) & -0.92 & - \\
\hline Tipo de espinas (Ramas espinosas) & -0.92 & - \\
\hline Pilosidad Nervadura Haz (Casi glabro) & 0.91 & - \\
\hline Pilosidad Nervadura Envés (Casi glabro) & 0.88 & - \\
\hline Pilosidad Lámina Envés (Casi glabro) & 0.87 & - \\
\hline Pilosidad Pecíolo. Envés (Muy piloso) & -0.85 & - \\
\hline $\begin{array}{l}\text { Tamaño Domacios Tercio } \\
\text { Medio (Ausentes) }\end{array}$ & -0.85 & - \\
\hline Pilosidad Ramas jóvenes (Muy pilosa) & -0.84 & - \\
\hline $\begin{array}{l}\text { Tamaño Domacios Tercio } \\
\text { Medio (Pequeños) }\end{array}$ & 0.83 & - \\
\hline $\begin{array}{l}\text { Pilosidad Nervadura Haz } \\
\text { (Moderadamente piloso) }\end{array}$ & -0.83 & - \\
\hline Forma Ápice Hoja (Agudo) & 0.82 & - \\
\hline Altura Individuo & 0.81 & - \\
\hline $\mathrm{N}^{\circ}$ total de Domacios & 0.79 & - \\
\hline $\begin{array}{l}\text { Pilosidad Lámina-Haz } \\
\text { (Moderadamente piloso) }\end{array}$ & -0.79 & - \\
\hline Pilosidad Pec. Envés_4 (Piloso) & - & 0.72 \\
\hline $\begin{array}{l}\text { Pilosidad Envés Lam_3 } \\
\text { (Escasamente piloso) }\end{array}$ & - & 0.71 \\
\hline D. Tipo_2 (Bolsillos con muchos pelos) & - & 0.66 \\
\hline $\begin{array}{l}\text { Pilosidad Envés Nerv_3 } \\
\text { (Escasamente piloso) }\end{array}$ & - & 0.63 \\
\hline $\begin{array}{l}\text { Pilosidad Envés Nerv_4 } \\
\text { (Moderadamente piloso) }\end{array}$ & - & 0.61 \\
\hline Simetría Hoja_2 (Simétrico) & - & 0.57 \\
\hline Simetría Hoja_1 (Asimétrico) & - & -0.57 \\
\hline
\end{tabular}

de Conglomerados (AC), Análisis de Varianza Multivariado con Permutaciones (PERMANOVA) y Análisis de Similitud (ANOSIM), para caracterizar y evaluar diferencias morfológicas entre los grupos de ejemplares colectados. Por último, se usó el programa R (R Core Team, 2015), paquete 
estadístico FactoMineR (Lê et al., 2008), para realizar la descripción de los clusters formados mediante Análisis de la Varianza Univariado. En base a ello se construyó una clave dicotómica útil para la diferenciación de los taxones.

\section{Resultados}

El Análisis de Componentes Principales de las variables vegetativas, altura y diámetro de los individuos retuvo 21 componentes, siendo las dos primeras las que explican el $40,6 \%$ de la variabilidad total estudiada (CP1: $31,4 \% / \mathrm{CP} 2$ : 9,2\%, ver Fig. 2A). En el Biplot resultante se observa que los ejemplares analizados se ordenan formando tres grupos claramente separados entre sí: uno de ellos agrupa individuos pre-identificados como C. tala (señalado en color azul), y los dos restantes a individuos pre-identificados como $C$. pallida (señalados en color rojo y verde) (ver Fig. 2A). Las variables y estados más fuertemente correlacionados, positivamente, a la CP1 son: tipo de domacios (bolsillos con pocos pelos), pilosidad del haz y envés de las hojas (casi glabro), tipo de corteza (rugosa), tamaño de domacios del tercio medio (pequeños), forma del ápice de la hoja (agudo), altura y número total de domacios/hoja. Mientras que las variables y estados correlacionados, negativamente, con la CP1 son: pilosidad del pecíolo (muy piloso), tipo de corteza (lisa), tipo de espinas (ramas espinosas), tamaño de domacios del tercio medio (ausentes), pilosidad de ramas jóvenes (muy pilosas), y pilosidad del haz de las hojas (moderadamente piloso). Por otro lado, las variables y estados positivamente correlacionados con la CP2 son aquellas relacionadas a la pilosidad de la lámina (haz y envés), pecíolo, domacios y simetría de la hoja (ver Tabla 1).

A partir del dendrograma resultante del AC, se visualiza un agrupamiento similar al obtenido en el ACP. Los tres grupos se forman al nivel de corte de 1,5 utilizando la distancia de Gower (ver Fig. 2B). Tanto en el ACP como en el AC, los individuos se ordenan y agrupan en tres conjuntos coincidentes con la identificación previa. Las variables reproductivas que fueron analizadas en este trabajo (ver Material Suplementario-Tabla 1) no fueron consideradas en estos análisis ya que, en la mayoría de los casos, los individuos con frutos se encontraban inmaduros y por lo tanto su desarrollo incompleto.
Para evaluar la significancia de la separación entre los tres grupos se realizaron los análisis de PERMANOVA y ANOSIM. Los resultados obtenidos (ver Tabla 2) demuestran la existencia de diferencias significativas ( $p$-valor $<0.05$ ) entre los tres conjuntos, con un $\mathrm{p}$-valor corregido por Bonferroni de 0,0003. Los estadísticos $\mathrm{F}$ y $\mathrm{R}$ asociados a cada análisis, confirman las diferencias y disimilitudes observadas. En este sentido, cabe destacar que los R-valores obtenidos en el ANOSIM son superiores a 0,5, y se acercan más a 1 en el caso de $C$. tala y $C$. pallida (grupo verde), indicando particularmente una elevada disimilitud entre dichos taxones.

Las variables y estados que se encuentran más ligados a cada grupo, y que permiten diferenciar a las entidades definidas en el análisis anterior son (Material Suplementario- Tabla 2), para el grupo azul (pre-identificados como C. tala): corteza rugosa; tipo de domacio (bolsillo con pocos pelos); altura y diámetro de los individuos mayor que en los demás grupos, longitud y ancho de la hoja y pecíolo con valores superiores a la de los otros grupos detectados; ausencia casi total de pilosidad del haz y envés de la lámina y nervaduras; gran cantidad de domacios principalmente en el sector inferior y medio de la lámina, siendo los primeros grandes y los últimos pequeños; morfología de la hoja ovado-lanceolada y el ápice agudo; contraste entre la lámina y las nervaduras destacado y lámina concolor; presencia de espinas de origen estipular, aunque con menor frecuencia se presentan individuos con espinas tanto de origen estipular como ramas espinosas; y presencia de pocas lenticelas en ramas adultas (Fig. 3). En el grupo rojo (pre identificados como C. pallida) se destacan: pilosidad del envés de la lámina(escasamente piloso), y pilosidad del envés del pecíolo (piloso); las nervaduras resultan ser escasamente a moderadamente pilosas, aunque escasamente pilosas en el haz; ramas adultas pilosas y las jóvenes muy pilosas; corteza lisa; domacios de tipo bolsillo con muchos pelos; presencia de ramas espinosas en todos los casos observados; y hoja concolora, con nervaduras no contrastantes con la lámina. Finalmente, en el grupo verde (pre identificados como C. pallida) los caracteres más representativos son: abundante pilosidad del pecíolo tanto en haz como envés, así como pilosidad moderada de la lámina y nervaduras en el haz y en el envés densamente 


\section{J. Asmus et al. - Identidad taxonómica de Celtis tala y Celtis pallida}

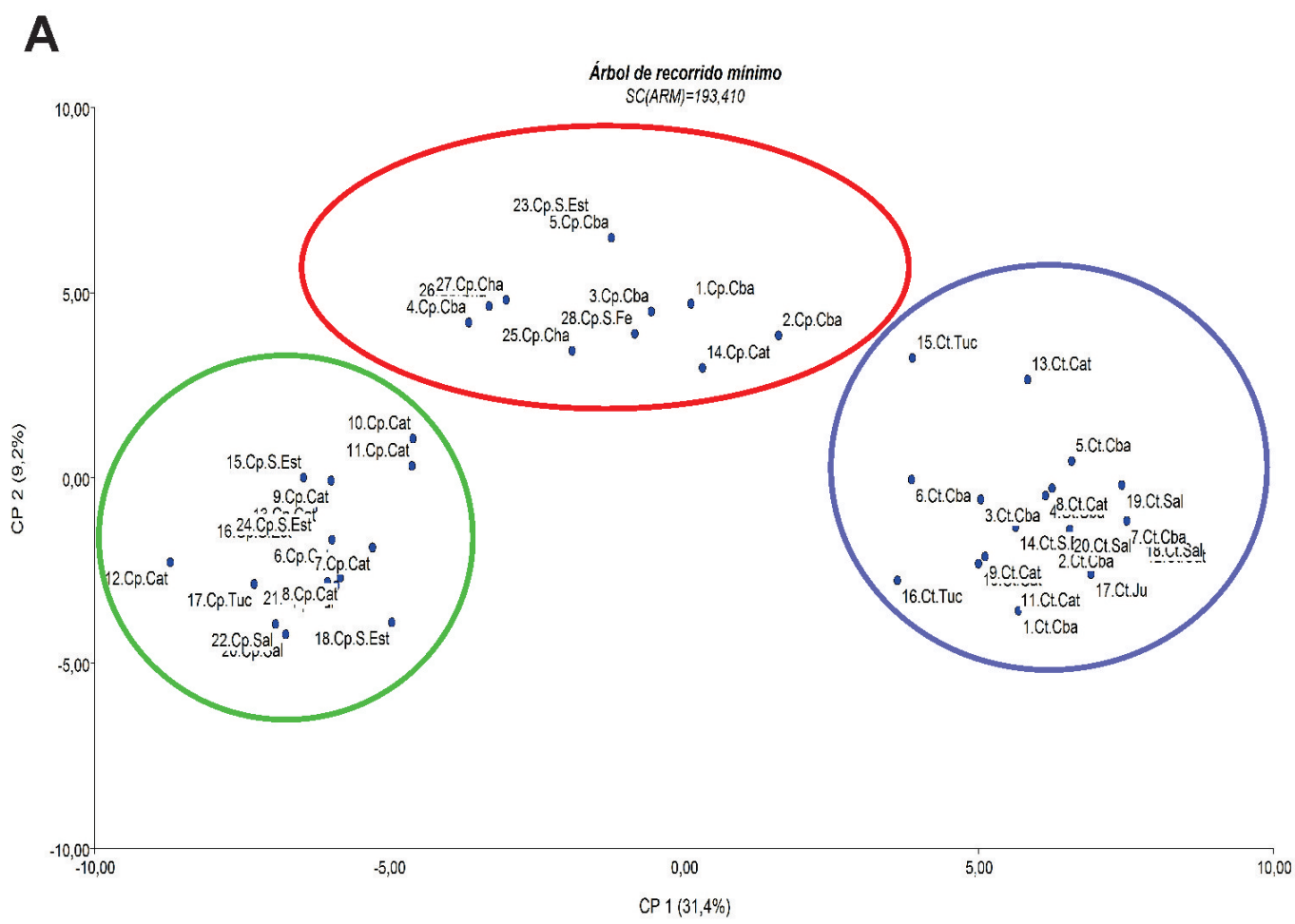

B
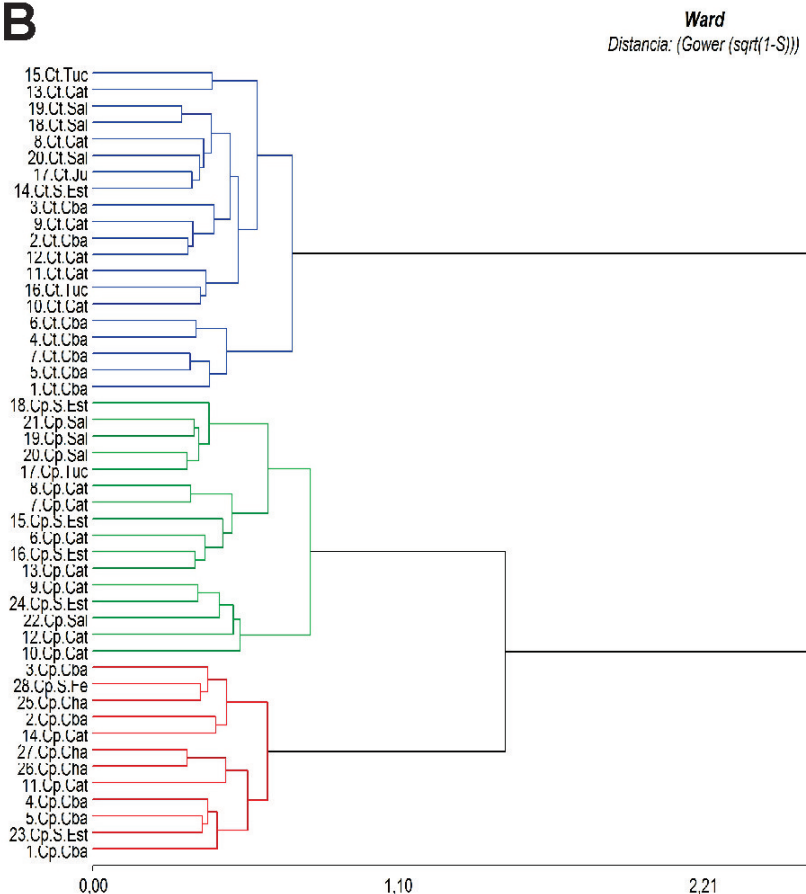

Fig. 2. Resultado del ACP y AC de 42 variables vegetativas, altura y diámetro sobre 48 individuos. A: Proyección de los individuos estudiados en relación a las componentes principales 1 y 2, Ct: $C$. tala; $\mathrm{Cp}: C$. pallida, según la identificación previa de los especímenes. B: Agrupamiento jerárquico (criterio de Ward). El eje lateral corresponde a la distancia de Gower. Los colores representan la partición en tres grupos a un nivel de corte de 1,5 . 
Tabla 2. Resultados del ANOSIM (R-valores)

y PERMANOVA (F-valores). Los p-valores

(corregidos por Bonferroni) $=0,0003$, para todas las comparaciones, en ambos análisis.

\begin{tabular}{|lccc|}
\hline \multicolumn{1}{|r}{ F-valor } & \multicolumn{3}{c|}{ P-valor } \\
\hline C. pallida & C. pallida & C. tala & C. pallida \\
C. tala & - & 0.898 & 0.558 \\
C. pallida & 12.39 & - & 0.969 \\
\hline
\end{tabular}

pilosas; domacios frecuentemente ausentes o muy pequeños; lámina discolor; forma de la hoja principalmente ovada con ápice obtuso y margen muchas veces semi-crenado; la presencia de ramas espinosas de origen caulinar, corteza lisa, ramas jóvenes muy pilosas; ausencia de contraste entre lámina y nervaduras y abundante presencia de lenticelas en las ramas.

\section{Clave para diferenciar a los taxones de Celtis tratados en el presente trabajo}

1. Árboles, con corteza rugosa. Espinas geminadas de origen estipular. Hojas ovado-lanceoladas con ápice agudo. Nervaduras de color más claro que el resto de la lámina. Haz y envés de la lámina y nervaduras casi glabros. Hojas concoloras. Domacios (2-20) del tipo bolsillo con pocos pelos, los basales de mayor tamaño que los demás. C. tala

1'. Arbustos, con corteza lisa. Ramas espinosas foliosas. Hojas ovadas con ápice obtuso, en menor medida emarginado o mucronado. Nervaduras de color similar al resto de la lámina. Hojas concoloras o discoloras. Domacios (0-7) del tipo bolsillo con muchos pelos.

... 2

2. Hojas concoloras. Haz y envés de la lámina escasamente piloso, con nervaduras y pecíolo moderadamente pilosos. Domacios (1-7) del tipo bolsillos con muchos pelos, los basales de mayor tamaño que el resto.

C. pallida var. pallida

$2^{\prime}$. Hojas discoloras. Envés blanquecino por la densa pilosidad. Haz de la lámina y nervaduras moderadamente pilosos y envés densamente piloso a muy piloso. Domacios ausentes o 2 basales del tipo bolsillos con muchos pelos. ....... C. pallida var. discolor

\section{Tratamiento taxonómico}

Celtis pallida Torr. var. pallida, en Emory, Rep. U.S. Mex. bound. 2: 203, pl. 50, 1859. Celtis tala Gillies ex Planch. var. pallida (Torr.) Planch., en D.C., Prodr. 17: 191, 1873. Celtis spinosa Spreng. var. pallida (Torr.) M.C. Johnst., Southw. Naturalist 2 (4): 172, 1957. Tipo: USA, Texas, Rio Grande, 1851-1852, Wright 1858 (Lectotipo: NY).

= Celtis tala Gillies ex Planch. var. chichape (Weed.) Planch. f. subpilosa Kuntze, Rev. Gen. Pl. 3 (3): 294. 1898. Tipo: Argentina, Santiago del Estero, Pinto, X-1892, Kuntze s.n. (Holotipo: NY, Isotipo: NY).

$=$ Celtis weddelliana (Planch.) Romanczuk, Hickenia 1(2): 7. 1976. Tipo: Argentina, Corrientes, II-1832, Bonpland 1211 (Lectotipo, P).

Arbustos de hasta de $5 \mathrm{~m}$ de altura, de corteza lisa. Ramas espinosas foliosas. Hojas concoloras, de 12-32 mm long. $\times 5-20 \mathrm{~mm}$ lat., láminas ovadas con ápice obtuso, en menor medida emarginado o mucronado. Nervaduras de color similar al resto de la lámina. Haz y envés de la lámina escasamente piloso, con nervaduras y pecíolo moderadamente pilosos. Domacios (1-7) del tipo bolsillos con muchos pelos, los basales de mayor tamaño que el resto. Frutos con pirenos de 3,5-4,0 mm long., levemente alveolados a casi lisos. (Fig. 4 y 5 ).

Celtis pallida Torr. var. discolor Hunz. \& Dottori, Kurtziana 9: 130, 1976. Celtis ehrenbergiana (Klotzsch) Liebm. var. discolor (Hunz. \& Dottori) Oakley \& D. Prado, Rojasiana 12 (1-2): 127, 2013. Tipo: Argentina, Prov. Catamarca, Dpto. Capayán, Sierra de Ambato, Quebrada de San Jerónimo, 5 km NW de Chumbicha, 19/II/1975, Hunziker et al. 22774 (Holotipo: CORD, Isotipo: MA).

$=$ Celtis tala Gillies ex Planch. var. gilliesiana Planchon f. velutina Herzog, Meded. Rijks-Herb. 27: 72, 1915. Tipo: Bolivia, Tarija, Pilcomayo, X/1910, Herzog 1096 (Lectotipo: G).

= Celtis sericea Romanczuck, Hickenia 1 (2): 5, 1976. Celtis pallida Torr. subsp. sericea (Romanczuck) Romanczuck, Darwiniana 21: 562, 1978. Tipo: Argentina, Prov. Jujuy, Dpto. San Pedro, San Lucas, 23/I/1976, Cabrera et al. 27532 (Holotipo: SI, Isotipo: P).

Difiere de la var. pallida por poseer hojas discoloras, con envés blanquecino por la densa 


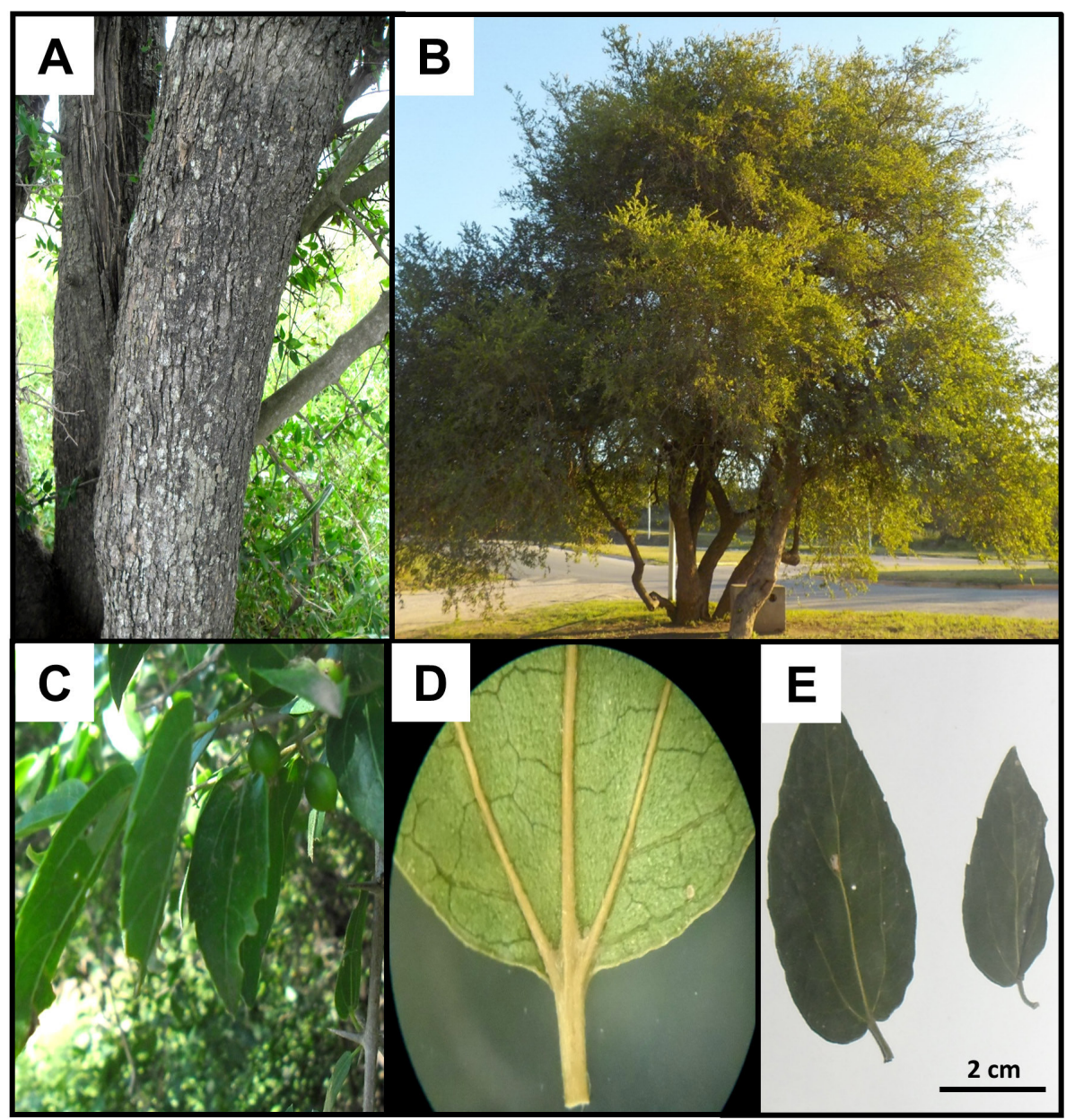

Fig. 3. C. tala. A: Rugosidad de la corteza. B: Aspecto de los individuos, de porte arbóreo. C: hojas, frutos inmaduros y espinas geminadas. D: Envés de la lámina casi glabro, contraste de color entre envés de la lámina y nervaduras, domacios basales. E: Hojas de morfología generalmente ovada-lanceolada.

pilosidad. Haz de la lámina y nervaduras moderadamente pilosas. Domacios ausentes o dos basales pequeños, del tipo bolsillos con muchos pelos. (Fig. 4 y 5).

Celtis tala Gillies ex Planch., Ann. Sci. Nat. Bot. Sér. 3, 10: 310, 1848. Celtis tala Gillies ex Planch. var. gilliesiana Planch., en D.C., Prodr. 17: 191, 1873. Tipo: Argentina, San Luis, Gillies s.n. (Lectotipo, K).

= Momisia integrifolia Wedd. Ann. Sci. Nat. Bot. Sér. 3, 18: 196, 1852. Celtis tala Gillies ex Planch. var. weddelliana Planch., en D.C., Prodr. 17: 191, 1873. Celtis spinosa Spreng. var. weddelliana
(Planch.) Baehni, Candollea 7: 204, 1936. Tipo: Brasil, Río Grande do Sul, Gaudichaud 1734 (Lectotipo, P).

$=$ Celtis spinosa sensu Baehni non Spreng.

Árboles de 3-12 (20) m de altura, de corteza rugosa. Espinas geminadas de origen estipular, rectas. Hojas concoloras de 25-50 mm long. $\times 10-$ $25 \mathrm{~mm}$ lat., ovado-lanceoladas con ápice agudo. Haz y envés de la lámina y nervaduras casi glabros. Domacios (2-20) del tipo bolsillo con pocos pelos, los basales de mayor tamaño que los demás. Frutos con pirenos rugosos, de 4-6 mm long. x 3-4 mm lat. (Fig. 3). 


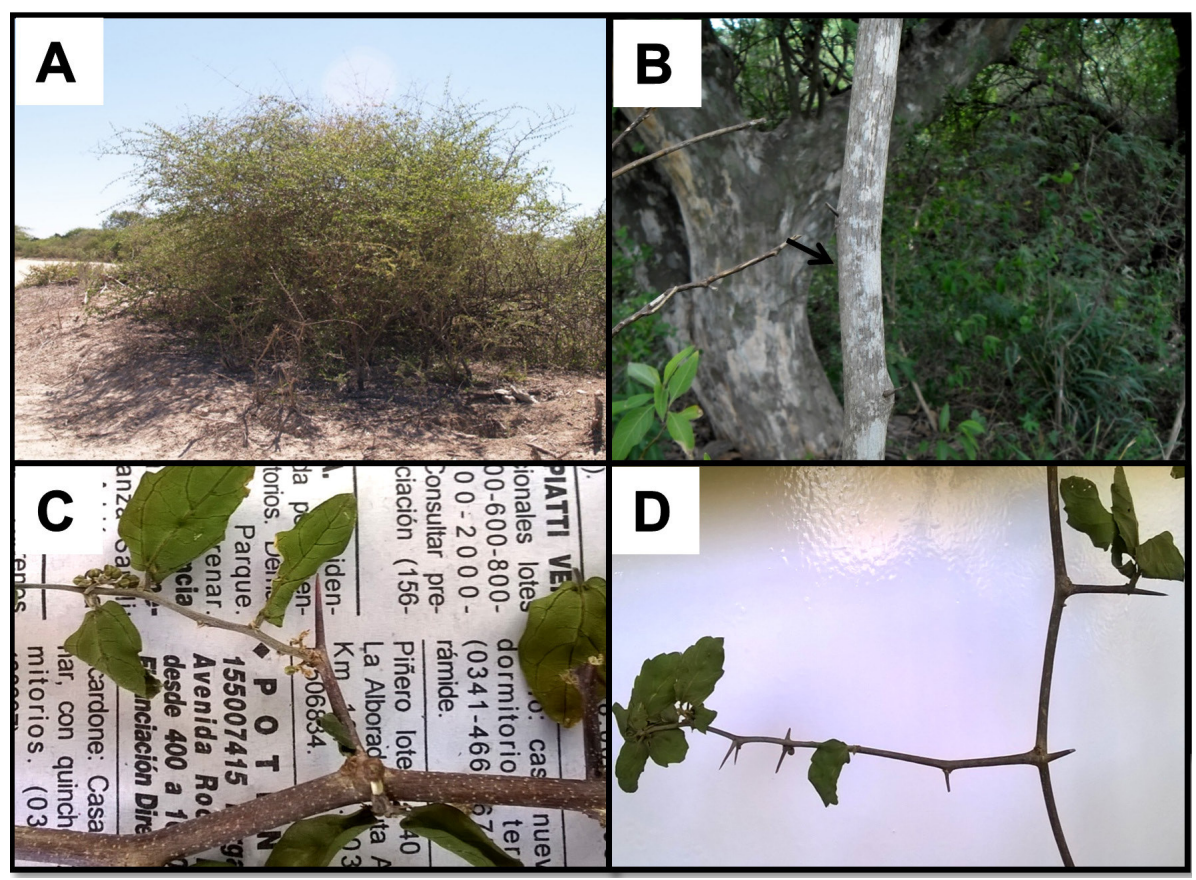

Fig. 4. C. pallida. A: Porte arbustivo de los individuos. B: Aspecto liso de la corteza. C- D: hojas, ramas con abundantes lenticelas y ramas espinosas.

\section{Discusión y Conclusiones}

En función de los resultados expuestos anteriormente, los antecedentes bibliográficos sobre los taxones estudiados en este trabajo, sumado a los extensos recorridos de campo y la larga experiencia de campo de varios de los autores, consideramos que los tres grupos que se distinguen en los análisis corresponden a: $C$. pallida var. pallida (grupo rojo); C. tala (grupo azul); y C. pallida var. discolor (grupo verde).

Con respecto a $C$. tala, nuestros resultados concuerdan con Hunziker \& Dottori (1976), Romanczuk \& del Pero de Martínez (1978) y Dottori \& Hunziker (1994), quienes otorgaron un rol central al aspecto, dimensiones y número de espinas, dimensiones de las hojas, cantidad y tamaño de domacios, dimensiones y aspecto de los pirenos y porte arbóreo de los individuos. Coincidentemente, en las claves dicotómicas elaboradas para la determinación de esta especie, aquellos autores mencionados consideran la morfología, ápice y margen de las hojas como caracteres diferenciales. Según el análisis realizado en el presente trabajo, predomina entre los especímenes colectados una morfología foliar ovada-lanceolada con ápice agudo para C. tala; sin embargo, también se observó una amplia variabilidad en esos caracteres entre los diferentes ejemplares de este taxón y entre las diferentes especies del género. La pilosidad foliar suele ser considerada un carácter muy variable y poco confiable para determinar especímenes; no obstante, en este estudio se detectó una uniforme escasez de pilosidad en lámina, nervaduras y pecíolo para todos los ejemplares de C. tala. Los pirenos no fueron considerados como relevantes en este estudio ya que los frutos de los especímenes recolectados se encontraban frecuentemente inmaduros. A pesar de ello, se observó que las dimensiones de los frutos y pirenos para C. tala son de mayor tamaño que para los otros taxones bajo estudio, hecho que también es destacado en la bibliografía (Hunziker \& Dottori, 1976; Dottori \& Hunziker, 1994; Novara, 2009).

Con relación a $C$. pallida, los caracteres diferenciales aquí destacados como críticos son similares a los que reconocen los autores que han trabajado en el grupo con anterioridad. Es así que Hunziker \& Dottori (1976) y Dottori \& Hunziker 


\section{J. Asmus et al. - Identidad taxonómica de Celtis tala y Celtis pallida}

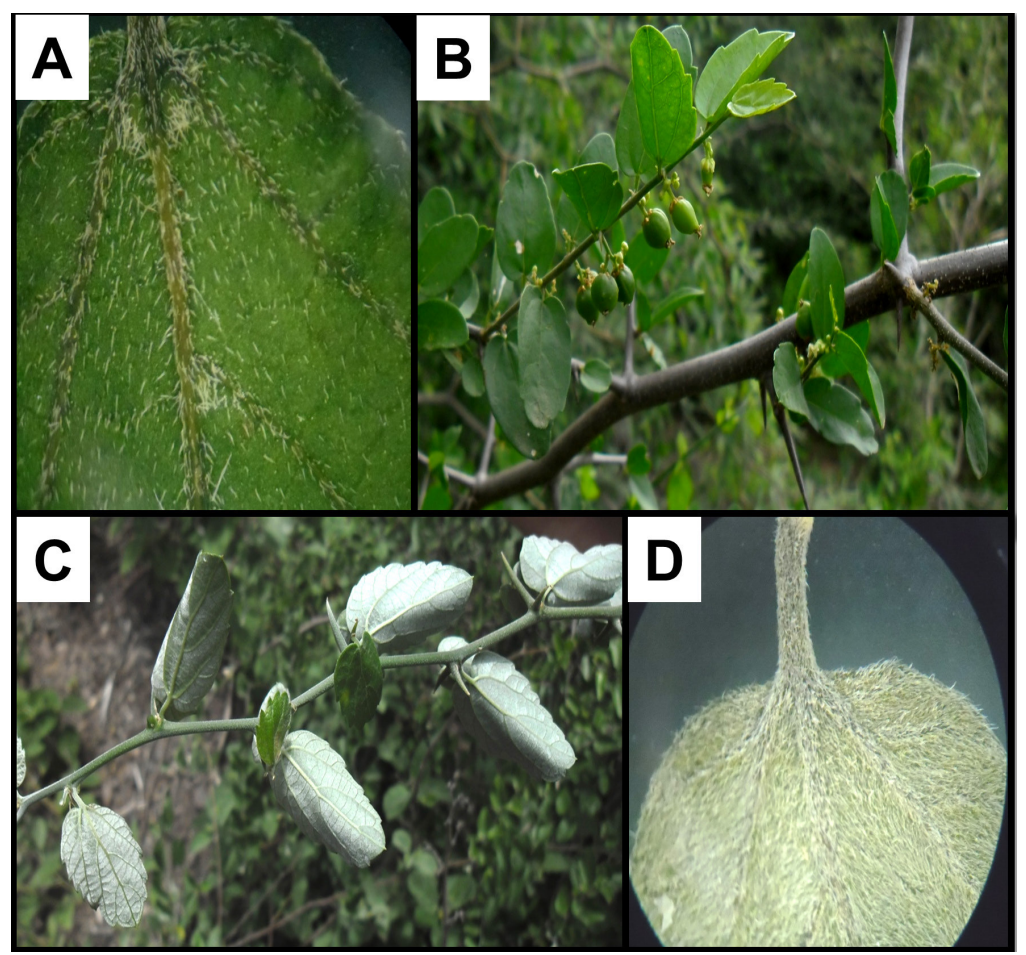

Fig. 5. C. pallida var. pallida: A: Pilosidad del envés de la lámina casi glabro con nervaduras moderadamente pilosas y domacios del tipo bolsillo con muchos pelos. B: hojas, frutos inmaduros y ramas espinosas. $C$. pallida var. discolor: C: hojas, con envés blanquecino. D: Detalle de la pilosidad en el envés de la lámina, pecíolo y nervaduras densamente piloso, y domacios imperceptibles.

(1994) consideran al porte arbustivo, la presencia de espinas foliosas y las dimensiones y aspecto de los pirenos como caracteres primordiales para diferenciarlo de C. tala. Cabe aclarar que Romanczuk \& del Pero de Martínez (1978) identificaron los mismos caracteres pero hacen referencia a espinas con nudos visibles y desarrollo de braquiblastos foliados, en vez de espinas foliosas. Posteriormente, Novara (2009) menciona los mismos caracteres y además suma la forma y margen de las hojas. Con respecto a las espinas foliosas o con nudos visibles que se mencionan ampliamente en la bibliografía, consideramos que son en realidad espinas de origen caulinar, es decir, ramas espinosas. A diferencia de C. tala, en $C$. pallida las ramas espinosas están siempre presentes, siendo una característica típica de la especie.

Por otra parte, se observa que los individuos pre-identificados como C. pallida se dividen en dos grupos. A partir de ello, y coincidentemente con
Hunziker \& Dottori (1976), consideramos que se trata efectivamente de las variedades $C$. pallida var. pallida y C. pallida var. discolor. Los abundantes caracteres similares entre ambas entidades, hace presumir efectivamente su parentesco. Por ejemplo, y para citar algunos: el aspecto liso de la corteza, abundancia de lenticelas, presencia de ramas espinosas invariablemente y las dimensiones y el hábito de los individuos (porte arbustivo). Los caracteres que diferencian a ambas entidades son los mismos que postularon distintos autores (Hunziker \& Dottori, 1976; Dottori \& Hunziker, 1994; Romanczuk \& del Pero de Martínez, 1978; Novara, 2009). Así, se observa que C. pallida var. discolor presenta una densa pilosidad en todo el cuerpo de la planta; particularmente en las hojas, las que se observan discolores debido a la presencia de una densa pilosidad en el envés de la misma. Por otra parte, los domacios en $C$. pallida var. pallida presentan una abundancia relativa, pero en menor cantidad que en C. tala y 
son del tipo bolsillo con muchos pelos, mientras que en C. pallida var. discolor en la mayoría de los individuos se presentan de a pares en la base, ocultos por la tupida pilosidad de la lámina o a veces ausentes. La morfología foliar en ambas variedades es muy variable; sin embargo, en $C$. pallida var. discolor hay una cierta predominancia de hojas ovadas, con ápice obtuso y margen medio y superior de la lámina semicrenado.

$\mathrm{Si}$ bien existen controversias en cuanto a la categoría que se corresponde con las entidades infraespecíficas de C. pallida (Romanczuk \& del Pero de Martínez, 1978, las consideraban subespecies), en este trabajo concordamos con el criterio de Hunziker \& Dottori (1976) y Dottori \& Hunziker (1994) y se reconocen dos variedades, ya que ambas poseen áreas de convivencia y existe en sus caracteres una variación continua.

Además, se encontraron algunos especímenes intermedios entre las agrupaciones correspondientes a C. pallida var. pallida y C. pallida var. discolor, es decir con caracteres compartidos. Estos individuos, pertenecientes en su mayoría a la provincia de
Catamarca, fueron colectados en la región de Chaco Serrano y Transición de éste a Selva Pedemontana, donde las poblaciones de ambas variedades están en contacto. En consecuencia, la variabilidad morfológica intermedia observada podría estar reflejando la heterogeneidad ambiental propia de dichos sectores de contacto entre regiones y taxones y/o sugiriendo la existencia de interfertilidad (híbridos) entre ambas variedades. No obstante, sería necesario realizar estudios de tipo molecular y cubrir el rango de distribución de los taxones al máximo posible ( $C$. pallida var. discolor se encuentra también en Bolivia y Paraguay), para llegar a conclusiones más certeras.

En términos taxonómicos, las tres entidades detectadas son consideradas actualmente como C. ehrenbergiana, a partir de la revisión de Berg \& Dahlberg (2001). Sin embargo, según Oakley \& Prado (2013), se hacen aquí las siguientes críticas a dicha revisión: 1- se utilizaron caracteres bastante variables para diferenciar las entidades, como por ejemplo la pilosidad de la lámina, mientras que caracteres de mayor relevancia

Tabla 3. Diferencias morfológicas entre los taxones de Celtis estudiados.

\begin{tabular}{|c|c|c|c|}
\hline \multirow{2}{*}{$\begin{array}{c}\text { Caracteres } \\
\text { morfológicosdiferenciales }\end{array}$} & \multicolumn{3}{|c|}{ Taxones } \\
\hline & Celtis tala & Celtis pallida var. pallida & Celtis pallida var. discolor \\
\hline Hábito de crecimiento & Árbol & Arbusto & Arbusto \\
\hline Tipo de Corteza & Rugosa & Lisa & Lisa \\
\hline Tipo de Espinas & $\begin{array}{l}\text { Espinas geminadas } \\
\text { de origen estipular }\end{array}$ & Ramas espinosas foliosas & Ramas espinosas foliosas \\
\hline Forma de Hojas & $\begin{array}{l}\text { Ovado-lanceoladas } \\
\text { con ápice agudo }\end{array}$ & $\begin{array}{c}\text { Ovadas con ápice } \\
\text { obtuso, en menor medida } \\
\text { emarginado o mucronado }\end{array}$ & $\begin{array}{l}\text { Ovadas con ápice } \\
\text { obtuso, en menor medida } \\
\text { emarginado o mucronado }\end{array}$ \\
\hline $\begin{array}{l}\text { Color nervaduras con } \\
\text { respecto a la lámina }\end{array}$ & $\begin{array}{l}\text { Nervaduras de color } \\
\text { más claro que el } \\
\text { resto de la lámina }\end{array}$ & $\begin{array}{l}\text { Nervaduras de color similar } \\
\text { al resto de la lámina }\end{array}$ & $\begin{array}{l}\text { Nervaduras de color similar } \\
\text { al resto de la lámina }\end{array}$ \\
\hline Pilosidad de la Hoja & $\begin{array}{l}\text { Haz y envés de la lámina } \\
\text { y nervaduras casi glabros }\end{array}$ & $\begin{array}{l}\text { Haz y envés de la lámina } \\
\text { escasamente piloso, con } \\
\text { nervaduras y pecíolo } \\
\text { moderadamente pilosos }\end{array}$ & $\begin{array}{l}\text { Haz de la lámina y nervaduras } \\
\text { moderadamente pilosos y envés } \\
\text { densamente piloso a muy piloso }\end{array}$ \\
\hline $\begin{array}{l}\text { Contraste de la lámina } \\
\text { (haz-envés) }\end{array}$ & Hojas concoloras & Hojas concoloras & $\begin{array}{l}\text { Hojas discoloras. Envés } \\
\text { blanquecino por la } \\
\text { densa pilosidad }\end{array}$ \\
\hline $\mathrm{N}^{\circ}$ de Domacios & $2-20$ & $1-7$ & $0-2$ \\
\hline Tipo de Domacios & $\begin{array}{l}\text { Bolsillo con pocos pelos. } \\
\text { Los basales de mayor } \\
\text { tamaño que los demás }\end{array}$ & $\begin{array}{l}\text { Bolsillo con muchos pelos. } \\
\text { Los basales de mayor } \\
\text { tamaño que el resto }\end{array}$ & $\begin{array}{l}\text { Bolsillo con muchos pelos. } \\
\text { Sólo basales o ausentes }\end{array}$ \\
\hline
\end{tabular}




\section{J. Asmus et al. - Identidad taxonómica de Celtis tala y Celtis pallida}

no fueron considerados (v.g. tipos de espinas, hábito); 2- no queda claro si todo el análisis fue hecho exclusivamente con material de herbario, o si se hizo trabajo de campo complementario, ni tampoco si fueron examinados en detalle todos los ejemplares tipo; y 3-tampoco se aclaran suficientemente los criterios utilizados para establecer sinonimias, cuando se tratan los taxones individualmente.

Otro autor que cuestiona a Berg \& Dahlberg (2001) es Henrickson (2010), quien realizó un estudio detallado del ejemplar tipo de $C$. ehrenbergiana y lo comparó con ejemplares mexicanos, con caracteres similares, determinados como C. iguanaea. Así, el carácter más representativo que relaciona a $C$. ehrenbergiana con C. iguanaea es la presencia de espinas solitarias y curvas, carácter típico de la segunda especie. A partir de esta conclusión, Henrickson (2010) postuló que C. ehrenbergiana debería considerarse un sinónimo de C. iguanaea.

En suma, en el presente trabajo se propone que $C$. tala y $C$. pallida son dos entidades completamente diferentes. Entre los caracteres de importancia taxonómica se pueden mencionar: porte de los individuos, textura de corteza, pilosidad de láminas, nervaduras y pecíolos, espinas estipulares/ramas espinosas, abundancia y aspecto de domacios (ver Tabla 3).

Además, surge claramente que para la flora del cono sur sudamericano, el binomio $C$. ehrenbergiana es un nombre que da lugar a dudas. Es decir, cuando se cita a esta entidad taxonómica en algún trabajo científico (v.g. Nughes et al. 2013), no se puede establecer en forma directa si los autores trabajaron en realidad sobre C. tala o sobre $C$. pallida, pues podría tratarse de cualquiera de ambas, a pesar de ser éstas radicalmente diferentes. Entonces, se propone aquí no usar el nombre $C$. ehrenbergiana hasta tanto se resuelva su verdadera posición taxonómica (por ejemplo, en el sitio web Flora del Cono Sur, disponible en www.darwin.edu.ar ) y rehabilitar los tradicionales nombres C. tala y C. pallida.

\section{Agradecimientos}

A la Facultad de Ciencias Agrarias, UNR. A los herbarios CORD, CTES, FCQ, LIL, LP, MCNS, $\mathrm{P}$, SI y UNR, por la autorización para examinar ejemplares. A Eugenia Pedrero, Ángeles Tessore, Roberto Salinas y Exequiel Agüero, por su ayuda en las colectas. Este trabajo fue parcialmente financiado por la Universidad Nacional de Rosario (Proyecto AGR-200). Los autores J.A., D.C., y D.P. agradecen al CONICET (Consejo Nacional de Investigaciones Científicas y Técnicas).

\section{Bibliografía}

BAEHNI, C. 1937. Les Celtis Sudamericains. Candollea 7: 189-214.

BERG, C.C. \& S.V. DAHLBERG. 2001. A Revision of Celtis subg. Mertensia (Ulmaceae). Brittonia 53: 66-81.

BRUSSA, C.A \& I.A. GRELA. 2007. Flora Arbórea del Uruguay. Con énfasis en las especies de Rivera y Tacuarembó. COFUSA. Montevideo, Uruguay.

DI RIENZO, J.A., F. CASANOVES, M.G. BALZARINI, L. GONZÁLEZ, M. TABLADA \& C.W. ROBLEDO. 2008. InfoStat, versión 2008. Grupo InfoStat, FCA, Universidad Nacional de Córdoba, Argentina.

DOTTORI, N. \& A. HUNZIKER. 1994. Celtidaceae. Flora Fanerogámica Argentina 2: 5-11.

HAMMER, Ø., D. HARPER \& P.D. RYAN. 2001. PAST: Paleontological statistics software package for education and data analysis. Palaeontol. Electron. 4: 9.

HENRICKSON, J. 2010. Comments on a revision of Celtis subgenus Mertensia (Celtidaceae) and the recognition of Celtis pallida. J. Bot. Res. Inst. Texas 4 : 287-293.

HUNZIKER, A. \& N. DOTTORI. 1976. Contribución al conocimiento sobre los talas (Celtis, Ulmaceae) de Argentina, con especial referencia a la región mediterránea I. Sobre una especie Austrosudamericana y sobre otra de área disyunta. Kurtziana 9: 103-140.

LÊ, S., J. JOSSE \& F. HUSSON. 2008. FactoMineR: an R package for multivariate analysis. J. Stat. Softw. 25: $1-18$.

MIQUEL, F.A.W. 1853. Urticineae: Celtis. In: C.F.P. VON MARTIUS (ed.) Flora Brasiliensis 4: 174182. P. Oldenburg, Leipzig.

NOVARA, L. 2009. Flora del Valle de Lerma (Salta, Argentina): Celtidaceae. Aportes botánicos de Salta-Ser. Flora 9: 1-20.

NUGHES, L., M. COLARES, M. HERNÁNDEZ \& A. ARAMBARRI. 2013. Morfo-anatomía de las hojas de Celtis ehrenbergiana (Celtidaceae) desarrolladas bajo condiciones naturales de sol y sombra. Bonplandia 22: 47-58. 
Bol. Soc. Argent. Bot. 53 (4) 2018

OAKLEY L.J. \& D.E. PRADO. 2013. Consideraciones sobre la identidad y delimitación de Celtis chichape (Wedd.) Miq. (Celtidaceae). Rojasiana 12: 117124.

SATTARIAN, A. 2006. Contribution to the biosystematics of Celtis L. (Celtidaceae) with special emphasis on the African species. $\mathrm{PhD}$ Thesis, Wageningen University, Wageningen.

ROMANCZUK, M.C. \& M.A. del PERO de MARTÍNEZ. 1978. Las especies del género Celtis (Ulmaceae) en la flora argentina. Darwiniana 21: 541-577.
ZULOAGA F.O., O. MORRONE \& M.J. BELGRANO (eds.). 2008. Catálogo de las plantas vasculares del Cono Sur (Argentina, Sur de Brasil, Chile, Paraguay y Uruguay). Monogr. Syst. Bot. Missouri Bot. Gard. 107, St. Louis.

Recibido el 8 de octubre de 2017, aceptado el 8 de noviembre de 2018. Editor: Massimiliano Dematteis. 


\section{J. Asmus et al. - Identidad taxonómica de Celtis tala y Celtis pallida}

\section{MATERIAL SUPLeMENTARIO}

\section{1- Especímenes colectados}

\section{Individuos pre identificados como Celtis tala:}

ARGENTINA. Prov. Catamarca: Dpto. El Alto: cerca de Infanzón; S-28,58580556 / O-65,43763889; 884 m.s.m; 24/11/2014; "Árbol de 7 m; diámetro 0,31 m; en bosque de cebil, tipo selva pedemontana transición al chaco; suelo pedregoso". 13-Ct-Cat- Dpto. Fray Mamerto Esquiú: camino a Villa Las Pirquitas; S-28,27197222 / O-65,73669444; 701 m.s.m; 22/11/2014; “Árbol de 6 m; diámetro 0,31 m; en Chaco Serrano; suelo pedregoso/arenoso". 8-Ct-Cat- San Antonio, Refugio de vida silvestre Merced de Allpatauca; S-28,41880556 / O- 65,69394444; 561 m.s.m; 22/11/2014; “Árbol de 7 m; diámetro 0,21 m; a un costado de campo sembrado; suelo pedregoso/limoso". 9-Ct-Cat- Dpto. Paclín: cerro San Antonio de Paclín; S-28,01666667 / O-65,69852778; 1106 m.s.m; 23/11/2014; “Árbol de 8 m; diámetro 0,131 m; en transición Chaco Serrano - Selva Pedemontana; suelo limoso/pedregoso".10.Ct-Cat- Dpto. Santa Rosa: pie de Cuestas de Alijilán a El Alto; S-28,18869444 / O-65,47230556; 576 m.s.m; 23/11/2014; “Árbol de $9 \mathrm{~m}$; diámetro 0,32 m; en Chaco Serrano, transición a Selva Pedemontana; suelo pedregoso/ con humus en superficie; al costado del camino". 11-Ct-Cat- Dpto. Valle Viejo: Cuesta del Portezuelo; S- 28,48197222 / O-65,61047222; 1196 m.s.m; 24/11/2014; “Árbol de 12 m; diámetro 0,30 m; en Chaco Serrano; suelo pedregoso/montañoso con grava; al costado de la ruta". 12-Ct-Cat- Prov. Córdoba: Dpto. Colón: Agua de Oro, calle El Quebracho, Barrio Parque tres Cóndores; S-31,01494444 / O-64,30391667; 832 m.s.m; 20/11/2014; "Árbol de $5 \mathrm{~m}$; diámetro 0,29 m; vegetación secundaria de Chaco Serrano; suelo limoso/pedregoso". 3-Ct-Cba- Dpto. Río Primero: oeste de Río Primero, Ruta Nac. 19; S-31,3065 / O-63,67477778; 256 m.s.m; 19/11/2014; “Árbol de 9 m; diámetro 0,50 m; en zona antropizada; suelo arenoso/limoso; entre la ruta y vías del ferrocarril, lotes agrícolas lindantes con plantaciones (cortinas) de Cupressus sp., nido de Myiopsitta monachus". 2-Ct-Cba- Dpto. Río Segundo: cerca de Villa del Rosario, Ruta 3; S-31,58433333 / O-63,65380556; 235 m.s.m; 19/11/2014; "Árbol de 6 m; diámetro 0,19 m; en sabana; suelo franco/limoso; estrecha franja (paralela a la ruta) de sabana de espinal". 1-Ct-Cba- Dpto Sobremonte: camino a Cerro Colorado; S-30,10613889 / O-63,89280556; 506 m.s.m; 20/11/2014; “Árbol de 2,5 m; diámetro 0,15 m; suelo limoso/arenoso". 6-Ct-Cba- Dpto. Totoral: entre Las Peñas y San José de la Dormida; S-30,54891667 / O- 64,00313889; 487 m.s.m; 20/11/2014; “Árbol de 9 m; diámetro 0,34 $\mathrm{m}$; relictos de bosque xerófilo antropizado, desmontado; suelo limoso/arenoso". 4-Ct-Cba- Oeste de Las Peñas; S-30,53805556 / O -64,14872222; 667 m.s.m; 20/11/2014; “Árbol de 9,5 m; diámetro 0,42 m; al costado del camino; suelo limoso/arenoso/pedregoso". 5-Ct-Cba- Dpto Tulumba: entre Villa Tulumba y Deán Funes, Ruta prov. 16; S-30,42836111 / O-64,2465; 926 m.s.m; 21/11/2014; “Árbol de 6 m; diámetro 0,21 m; en Chaco Serrano; suelo Limoso/pedregoso". 7-Ct-Cba- Prov. Jujuy: Dpto. El Carmen: Ruta 9, cerca de El Carmen; S-24,40602778 / O- 65,28080556; 1197 m.s.m; 29/11/2014; “Árbol de 13,5 m; diámetro 0,61 m; Ruderal, Vegetación secundaria al lado de la ruta, cerca de cultivo de tabaco; suelo franco/limoso". 17-Ct-Ju- Prov. Salta: Dpto. Capital: Monolito a Güemes, Cañada (quebrada) de la Horqueta; S-24,86708333 / O-65,21002778; 1150 m.s.m; 30/11/2014; "Árbol de 13 m; diámetro 0,30 m; Selva Pedemontana muy antropizada; suelo pedregoso/limoso; con plantas parásitas, pocas hojas". 19-Ct-Sal- Camino a Cuchihuman, ruta 34 hacia el este; S-24,89416667 / O-65,00763889; 858 m.s.m; 30/11/2014; "Árbol de 8,7 m; diámetro 0,20 m; en Chaco muy degradado; suelo limoso". 20-Ct-Sal- Dpto La Caldera: Cuesta del Gallinato; S-24,67702778 / O- 65,35291667; 1288 m.s.m; 29/11/2014; “Árbol de 9,5 m; diámetro 0,43 m; Presencia de cartel que indica que es transición entre Chaco Serrano y Selva Pedemontana; sitio bastante antropizado". 18-Ct-Sal- Prov. Santiago del Estero: Dpto. Choya: Villa La Punta, Sierras de Guasayán (parte baja); S-28,37208333 / O-64,80061111; 425 m.s.m; 25/11/2014; “Árbol de 12,3 m; diámetro 0,62 m; en Chaco Serrano; suelo pedregoso con grava/suelto; ejemplar acostado". 14-Ct-S.Est- Prov. Tucumán: Dpto. Burruyacu: Aguas Blancas; S-26,36952778 / O-64,77847222; 732 m.s.m; 26/11/2014; “Árbol de 14 m; diámetro 0,21 m; en relictos de Selva Pedemontana; suelo pedregoso con humus; se observan otros ejemplares del mismo tamaño en la zona". 15-Ct-Tuc- Ruta 336, camino a 


\section{Bol. Soc. Argent. Bot. 53 (4) 2018}

Burruyacu; S -26,54641667 / O-64,65838889; 433 m.s.m; 27/11/2014; “Árbol de 4 m; diámetro 0,28 m; en zona antropizada, costado de ruta de campo agrícola; suelo franco/limoso”. 16-Ct-Tuc-

\section{Individuos pre identificados como Celtis pallida}

ARGENTINA. Prov. Catamarca: Dpto El alto: al este de Infanzón; S-28,61794444 / O-65,39652778; 707 m.s.m; 24/11/2014; "Arbusto de 0,70 m de longitud; en bosque de cebilar; suelo limoso calcáreo/ pedregoso; se observan en el sitio ejemplares de hasta $2 \mathrm{~m}$, probablemente su presencia se deba a la actividad ganadera del lugar". 14-Cp-Cat- Dpto. Fray Mamerto Esquiú: camino a Villa Las Pirquitas; S- 28,27536111 / O-65,73322222; 712 m.s.m; 22/11/2014; "Arbusto de 0,80 m de longitud; en Chaco Serrano; suelo pedregoso/arenoso; en sotobosque, debajo de Acacia praecox y Prosopis chilensis". 6-CpCat- Camino a Villa las Pirquitas S-28,27422222 / O-65,73352778; 716 m.s.m; 22/11/2014; "Arbusto de 1,5 m de longitud; diámetro de 0,11 m; en Chaco Serrano; suelo arenoso; en ladera, al costado de un camino, ambiente antropizado, planta de sol, adyacente a Larrea divaricata y Ruprechtia apetala". 7-CpCat- Camino a Villa Las Pirquitas; S-28,27422222 / O-65,73352778; 716 m.s.m; 22/11/2014; "Arbusto de $2 \mathrm{~m}$ de longitud; diámetro de 0,16 m; en Chaco Serrano; suelo arenoso". 8-Cp-Cat- Camino a Villa Las Pirquitas; S-28,27197222 / O-65,73669444; 701 m.s.m; 22/11/2014; "Arbusto de 0,60 m de longitud; en Chaco Serrano; suelo pedregoso/arenoso". 9-Cp-Cat- San Antonio, Refugio de Vida Silvestre Merced de Allpatauca; S-28,41941667 / O-65,69011111; 565 m.s.m; 22/11/2014; "Arbusto de 1,9 de longitud; diámetro de 0,035 m; en Chaco Serrano; suelo pedregoso/limoso". 10-Cp-Cat- Dpto Paclín: Cerro San Antonio de Paclín; S- 28,01666667 / O-65,69852778; 1106 m.s.m; 23/11/2014; "Arbusto de 2 m de longitud; diámetro de 0,05 m; en transición Chaco Serrano-Selva Pedemontana; suelo limoso/pedregoso; hojas pubescentes, tallos jóvenes pubescentes". 11-Cp-Cat- Dpto Santa Rosa: Pie de Cuestas de Alijilán Al Alto; S-28,18966667 / O-65,47227778; 608 m.s.m; 23/11/2014; "Arbusto de 1,5 m de longitud; diámetro de 0,022 m; en transición Chaco Serrano-Selva Pedemontana; suelo pedregoso/con humus en superficie". 12-Cp-Cat- Dpto Valle Viejo: Cuesta del Portezuelo; S-28,47113889 / O-65,61830556; 948 m.s.m; 24/11/2014; "Arbusto de 1mt. de longitud; diámetro de 0,022 m; en Chaco Serrano; suelo rocoso/montañoso con grava; ejemplar con hojas pequeñas, muchas hojas en las espinas, espinas muy grandes; Ubicado en la ladera del cerro, muy seco". 13-Cp-Cat- Prov. Chaco: Dpto. Almirante Brown: entre Río Muerto y Los Frentones; S- 26,336 / O-61,51872222; 146 m.s.m; 01/12/2014; "Arbusto de 2,5 m de longitud; bosque Chaqueño degradado; suelo franco/limoso; hojas no pubescentes, sin envés blanco". 25-Cp-Cha- Dpto. O'higgins: Ruta 95, cerca de San Bernardo; S-27,29761111 / O-60,67419444; 94 m.s.m; 02/12/2014; "Arbusto de 0,60 m de longitud; en bosque Chaqueño degradado con intrusión de Patagonula americana; suelo franco; creciendo a la sombra". 26-Cp-Cha- Ruta 95, cerca de San Bernardo; S-27,29761111/ O-60,67419444; 94 m.s.m; 02/12/2014; "Arbusto de 1,60 m de longitud; en bosque Chaqueño degradado con intrusión de Patagonula americana; suelo franco; creciendo al sol, espinas de hasta $5 \mathrm{~cm}$ con nudos". 27-Cp-Cha- Prov. Córdoba: Dpto. Colón: Agua de Oro, calle El Quebracho, Barrio Parque tres Cóndores; S-31,01494444 / O-64,30391667; 832 m.s.m; 20/11/2014; “Arbusto de 2,5 m de longitud; en vegetación secundaria de Chaco Serrano; suelo limoso/pedregoso; piedras en afloramiento". 1-Cp-Cba- Dpto. Ischilin: noroeste de Quilino, Ruta 60; S-30,01483333 / O-64,58763889; 235 m.s.m; 21/11/2014; "Arbusto de 1,80 m de longitud; suelo arenoso". 4-Cp-Cba- Noroeste de Quilino, Ruta 60; S-30,01483333/ O- 64,58763889; 235 m.s.m; 21/11/2014; "Arbusto de 1,40 m de longitud; en bosque xerófilo del Chaco árido; suelo arenoso". 5-Cp-Cba- Dpto. Sobremonte: camino a Cerro Colorado; S-30,10613889 / O-63,89280556; 506 m.s.m; 20/11/2014; "Arbusto de 0,80 m de longitud; suelo limoso/arenoso". 3-Cp-Cba- Dpto. Totoral: entre Las Peñas y San José de la Dormida; S-30,54261111 / O-64,01711111; 514 m.s.m; 20/11/2014; "Arbusto de 1,10 m de longitud; suelo limoso/arenoso". 2-Cp-Cba- Prov. Salta: Dpto. Anta: estancia La Andorrana, entre Tolloche y Talavera; S-25,51569444 / O-63,57638889; 283 m.s.m; 01/12/2014; “Arbusto de 2,5 m de longitud; diámetro de 0,022 m; en Chaco Occidental; suelo franco/limoso; hojas muy grandes pubescentes". 22-Cp-Sal- Dpto. Capital: camino a Guemes y Monolito; S-24,82916667 / O-65,17458333; 989 m.s.m; 30/11/2014; "Arbusto de 1,72 m de longitud; en Chaco Serrano; suelo pedregoso/limoso". 19-Cp-Sal- Camino a Cuchihuman; S-24,89416667 / O-65,00763889; 858 m.s.m; 30/11/2014; "Arbusto 


\section{J. Asmus et al. - Identidad taxonómica de Celtis tala y Celtis pallida}

de 1,70 m de longitud; en Chaco degradado; suelo limoso; parece var.discolor”. 20-Cp-Sal- Dpto. Metán: Ruta 18, cerca de El Galpón; S-25,38527778 / O-64,77541667; 587 m.s.m; 01/12/2014; “Arbusto de 1,70 $\mathrm{m}$ de longitud; transición pedemontana-chaco; suelo pedregoso con humus; hojas pubescentes, envés blanquecino". 21-Cp-Sal- Prov. Santa Fe: Dpto. 9 de julio: entrada a Pozo Borrado, ruta 95; S-28,97805556 / O-61,60530556; 81 m.s.m; 02/12/2014; “Arbusto de 2 m de longitud; en intrusión de Espinal en región Chaqueña; suelo franco, con problemas de alcalinidad". 28-Cp-S.Fe- Prov. Santiago del Estero: Dpto Choya: Villa La Punta, Sierras de Guasayán (parte baja); S-28,37208333 / O-64,80061111; 425 m.s.m; 25/11/2014; "Arbusto de 2,20 m de longitud; diámetro de 0,06 m; en Chaco Serrano; suelo pedregoso con grava/suelto; algunas hojas pubescentes, otras no”. 15-Cp-S. Est - Villa La Punta, Sierras de Guasayán (parte baja); S-28,37208333 / O-64,80061111; 425 m.s.m; 25/11/2014; "Arbusto de 1,20 m de longitud; en Chaco Serrano; suelo pedregoso con grava/suelto; envés de la hoja blanco brillante, con estructuras redondas pubescentes podrían ser agallas, parásitos u algún otro bicho”. 16-Cp-S.Est- Dpto. Copo: Ruta 16 entre Monte Quemado y Los Tigres; S-25,85511111 / O-62,71866667; 234 m.s.m; 01/12/2014; “Arbusto de $3 \mathrm{~m}$ de longitud; en fachinal de Chaco degradado; suelo limoso; hojas no pubescentes ni seríceas". 23-Cp-S. Est- Ruta 16 entre Monte Quemado y Los Tigres S- 25,85511111 / O-62,71866667; 234 m.s.m; 01/12/2014; "Arbusto de 1,62 m de longitud; fachinal de Chaco degradado; suelo limoso; hojas pubescentes pero no con envés blanquecino". 24-Cp-S.Est- Dpto. Pellegrini: camino a La Fragua; S-26,14161111 / O-64,39175; 383 m.s.m; 27/11/2014. "Arbusto de 2,80 m de longitud; diámetro de 0,06 m; en Chaco semiárido (camino a Cerro El Remate); suelo limoso profundo; pocas hojas, envés blanquecino”. 18-Cp-S.Est- Prov. Tucumán: Dpto. Burruyacu: Aguas Blancas; S-26,37802778 / O-64,74502778; 655 m.s.m; 26/11/2014; "Arbusto de $0,80 \mathrm{~m}$ de longitud; diámetro de $0,022 \mathrm{~m}$; en transición/mezcla de pedemonte y chaqueño; bosque residual de cebil y horco quebracho; suelo pedregoso; envés de la hoja blanquecina". 17-Cp-Tuc-

\section{2 - Material adicional examinado}

\section{Celtis tala:}

ARGENTINA. Prov. Catamarca: Dpto. Ambato: Los Varela (1 km W, camino a Humaya); 1490 m.s.m; 28/03/1995; "Arbol de 4-5 mts de altura, frutos amarrillo-anaranjados; En pastizal degradado con estrato arbóreo"; Saravia Toledo et al. 12962 (CTES). Dpto. Fray Mamerto Esquiú: San Antonio, Jardín zoológico y botánico San Antonio; 20/09/1991; “Árbol de 8-10 mts de altura, flores verdosas, frutos inmaduros"; Ferrucci et al. 807 (CTES). Dpto. Paclín: La Viña, alrededor del lago del dique de Sumampa; 09/11/1993; "Frutos anaranjados"; Rotman \& Ahumada 1106 (CTES, JUA). Prov. Córdoba: Dpto. Cruz del Eje: Ruta de Villa del Soto a Salsacate, $15 \mathrm{~km}$ al sur de V. del Soto; 10/02/1973; Martínez 13822 (CTES, BAA). Ruta 38 km 865, camino entre Cruz del Eje y V. de Soto; 10/02/1973; "3 m de altura”; Martínez 13823 (CTES, BAA). Dpto. Unión: Bell Ville, Parque Tau; 24/01/1983; “Arbol de $8 \mathrm{mts}$, frutos maduros negros” Ferrucci 180 (CTES). Bell Ville, Parque Francisco Tau; 13/10/1992; “Árbol de 5 m de altura, flores verdosas; En margen del río Ctalamochita”; Ferrucci 625 (CTES). Ballesteros, 3 km al sur; 12/03/1985; "Arbol, ramas arqueadas"; Krapovickas \& Vanni 39775(CTES). Prov. Entre Ríos: Dpto. Federación: Santa Ana; 15/10/1968; "Flores blancas"; Gómez Sosa 95 (CTES). Dpto. Paraná: Paraná, Parque Gral. San Martín; 01/11/1968; "Arbolito de 3 m de altura. En barranca de río"; Boelcke \& Correa 9179 (CTES, BAA). Prov. Jujuy: Dpto. Capital: Los Perales; 08/06/1984; "Perímetro de $50 \mathrm{~cm}$, frutos naranja"; Corro et al. 16 (JUA). Dpto. El Carmen: Perico, río Perico; 06/01/1971; “3 m de altura”; Krapovickas \& Cristóbal 17525 (CTES). Dique Las Maderas; 19/12/1996; Protomastro 1241 (CTES, MCNS). Prov. La Rioja: Dpto. Capital: Ruta Nacional 75 entre Sanagasta y La Rioja; 13/12/1988; "Arbol de 5 m"; Biurrun 2515 (CTES, IZAC). Dpto. Chamical: a $300 \mathrm{mts}$ de Santa Lucía rumbo a Ruta Nac. 79; 21/10/1988; "Arbol de $8 \mathrm{~m}$, $40 \mathrm{~cm}$ de diámetro"; Biurrun 2495 (CTES, IZAC). Prov. Salta: Dpto. Anta: Parque Nacional El Rey, A ${ }^{\circ}$ Aguas Negras; 02/11/1981; "Flor blanca-amarillenta"; Brown 1567 (CTES). Finos del Rey; 08/11/1979. “Árbol 10 m de altura, diámetro de 0,35 m”; Schinini 19522 (CTES). Dpto. Cafayate: Cafayate, Barrio San Isidro; 1800 m.s.m.; 31/05/1905; "Árbol de 4-5 m de altura con frutos maduros naranja”; Romanczuk 353 (CTES). Dpto.Capital: 3 km de Salta, camino a San Lorenzo, La Loma; 10/04/1980; “Arbolito 3-4 m de altura; "En lomada al cerca de un arroyo"; Krapovickas \& Schinini 35983 (CTES). Dpto. Chicoana: 


\section{Bol. Soc. Argent. Bot. 53 (4) 2018}

Ruta 68, cerca dpto. La Viña, Chaco Humedo; 25/01/2007; “Arból de 5 m con frutos inmaduros verdes”; Paula-Souza 7756 (CTES, ESA). Dpto. Metán: 14 km NW de El Tunal; 600 m.s.m, 04/04/1980; “Árbol de $7 \mathrm{~m}$ de altura"; Krapovickas \& Schinini 35727 (CTES). Dpto. Rosario de La Frontera: $1 \mathrm{~km}$ W de Horcones; 27/01/2007; "Arbolito de 3 m de altura, frutos inmaduros verdes"; Paula-Souza 8013 (CTES, ESA). Prov. San Juan: Dpto. Valle Fértil: 7 km del desvío de ruta prov. 510 en dirección E a Los Bretes; 11/03/1998; "Arbol 5-6 m de altura, fruto anaranjado"; En Monte; Fortunato 5967 (CTES, BAB). Prov. San Luis: Dpto. Chacabuco: Ruta Provincial 40, 5 km oeste de Papagallo; 08/02/1999; "4 m de altura, suelo arenoso y seco"; Seijo 1834 (CTES). Prov. Santa Fe: Dpto. San Lorenzo: Monte Histórico; 27/09/1976; "Arbol 6 - 7 m de altura"; Lewis 1434 (UNR). Monte Histórico; 21/09/1982; "3 m de altura"; Pire 3795 (UNR). Prov.Santiago del Estero: Dpto.Ojo de Agua: Balneario próximo a Ojo de Agua; 10/11/1986; "Flor blanco-amarillenta"; Pérez Moreau \& Petetin 3744 (CTES, BAB). Prov.Tucumán: Dpto. Burruyacu: Alto de Medina; 09/10/1965; "5-8 m de altura"; Schulz 9534 (CTES). BRASIL. Rio Grande do Sul: año 1833; Gaudichaud 1734 (P). URUGUAY. Dpto. Montevideo: Montevideo; King s.n. (K, foto 7267). Dpto. Tacuarembó: Ruta 31, a 15 km W de Tacuarembó; 22/01/1995; "Árbol de 12 m de altura y $160 \mathrm{~cm}$ de diámetro; Fruto maduro amarillo, carnoso"; "Especimen solitario al costado de la ruta sobre un puente"; Pedersen 16224 (CTES, CP).

\section{C. pallida var. pallida}

ARGENTINA. Prov. Catamarca: Dpto. Ancasti: El Barrial; 28/1946; "2 m de altura, con flor blanca"; Brizuela 77 (CTES, LIL). Dpto. La Paz: Palo Cruz, Las Tejas; 09/03/1945; "En fruto"; Brizuela 403 (CTES, LIL). Prov. Chaco: Dpto. 9 de julio: Las Breñas; 29/10/1959; "1,5-2,5 m de altura"; Schulz 10813 (CTES). Dpto. 12 de Octubre: Gancedo; 03/01/1975; "2,5 m de altura"; Krapovickas \& Cristóbal 27168 (CTES). Dpto. $1^{\circ}$ de Mayo: Colonia Benitez; 12/1937; Schulz 2329 (CTES). Dpto. Comandante Fernández: Napenay, Ruta Nac. 16; 29/12/1970; "2 m de altura, frutos amarillos"; Krapovickas \& Cristóbal 17300 (CTES). Dpto. Gral. Guemes: 17 km al N de Fuerte Esperanza en direccion a Nueva Pompeya; 14/12/1999; "1-2 m de altura, flor blanca"; Fortunato 6415 (CTES, BAB). 2 km al SE de Pte. Esperanza en dirección a Castelli; 06/03/2000; "2 m de altura, fruto rojo-anaranjado"; Fortunato 6627 (CTES, BAB). Camino de Fuerte Esperanza a Taco Pozo; 30/10/1988; "En quebrachal con "palo santo"; Schinini \& Pire 24916 (CTES). Dpto. Independencia: $5 \mathrm{~km}$ al sur de la Ruta Nac. 16, a $24 \mathrm{~km}$ al Oeste de Roque Saenz Peña; 138 m.s.m.; 21/03/2006; Aliscioni 636 (CTES, SI). Ruta 16, 15 km NW de Avia Terai; 01/11/1974; "3 m de altura, flores blancas"; Schinini et al 10018 (CTES). Dpto. Libertador Gral. San Martin: Campo del Sr. Eitrich, 4,5 km W de empalme de ruta vecinal con ruta prov. $\mathrm{N}^{\circ} 4$ a 5,5 km N del Parque Provincial Pampa del Indio; 10/03/2004; "2 m de altura, borde de bosque chaqueño"; Tressens \& Ferreira 7063 (CTES). Prov. Córdoba: Dpto. Cruz del Eje: Ruta de Villa del Soto a Salsacate, $15 \mathrm{~km}$ al sur de V.del Soto; 10/02/1973; Martínez 12820 (CTES). Prov. Corrientes: Dpto. Bella Vista: Ruta 12, 7 km N de San Roque; 27/03/1976; Schinini \& Martínez Crovetto 12851 (CTES). Dpto. Capital: Ruta 5, 12 km SE de Ruta 12; 11/06/1981; "2,5 m de altura. En quebrachal"; Tressens \& Schinini 1275 (CTES). Ruta 5, $12 \mathrm{~km}$ SE de Ruta 12; 15/03/1975; "2 m de altura. En quebrachal”; Schinini 10978 (CTES). Ruta 12, 20 km NE de Corrientes, "Granja yatay"; 22/01/1976; "1,5-2 m de altura, En quebrachal”; Schinini 12495 (CTES). Dpto. Curuzú Cuatiá: Ea María Azucena, Ruta 25, 46 km W de Curuzú Cuatiá; 08/01/1977; "2 m de altura, flores blancas. En campos altos"; Schinini \& Ahumada 13909 (CTES). Dpto. Esquina: Quinta Los Olivos; 11/03/1975; Krapovickas et al. 27358 (CTES). 26 km SE de Libertador, Ea. La Blanca; 12/03/1975; "3 m de altura. En bosque abierto, suelo bajo"; Krapovickas et al. 27439 (CTES). Pueblo Libertador, arroyo Barrancas; 15/03/1975; "1 m de altura, con flores blancas"; Krapovickas et al. 27818 (CTES). Arroyo Barrancas y Ruta 126; 20/10/1977; "En borde de bosque"; Ahumada et al. 1080 (CTES). 47 km W de Sauce, Ruta 126; 23/10/1977; "Borde de salitral"; Ahumada et al. 1366 (CTES). 4 km S de Ruta 126, camino de Tres Bocas a Paso Yunque; 13/03/1975; "1 m de altura, con flores blancas. En algarrobal”; Krapovickas et al. 27656 (CTES). Dpto. Lavalle: Río Santa Lucía y Ruta 27; 01/03/1980; "2 m de altura, con flores verdosas. En bosque abierto. Suelo salitroso"; Ahumada et al.3400 (CTES). Dpto. Mercedes: Camino a Mercedes a Paso de los Libres; 17/09/1979; "5 m de altura. En quebrachal”; Schinini et al. 18666 (CTES). Cerca de Yofré; 13/04/1979; "1,5 m de altura. Fruto suculento anaranjado"; Pedersen 12450 (CTES, CP). 75 km N de 


\section{J. Asmus et al. - Identidad taxonómica de Celtis tala y Celtis pallida}

Mercedes, Laguna Trin, Ea. Culantrillar; 24/10/1975; "2 m de altura, con flores blancas. En bosque abierto con algarrobo y ñandubay"; Schinini et al. 11652 (CTES). Dpto. Saladas: $8 \mathrm{~km} \mathrm{~S}$ de San Lorenzo; 09/10/1994; "1,5 m de altura. En quebrachal abierto. Suelo arcilloso"; Krapovickas et al. 45622 (CTES). Dpto. San Luis del Palmar: Ruta 6, 16 km SE de S.L. del Palmar; 24/10/1976; "2-3 m de altura. Flores blanquecinas. En quebrachal. En suelo arcilloso"; Schinini \& Cristóbal 13685 (CTES). 10 km SE de San Luis del Palmar, Ruta 6; 26/09/1973; "Interior del monte"; Quarín \& Tressens 1353 (CTES). Dpto. Sauce: 35 km N de Sauce, Ruta 12; 21/10/1977; "En bosque abierto"; Ahumada et al. 1203 (CTES). Prov. Entre Ríos: Dpto. La Paz: Santa Elena, 14/03/1962; Burkart 23302 (CTES, SI). Dpto. Victoria: Laguna de los Pescados; 05/10/1977; "2-3 m de altura"; Pedersen 11910 (CTES, CP). Prov. Formosa: Dpto. Bermejo: Ruta 81 a 1 km W de Pozo del Mortero; 171 m.sm; 14/01/2002; "1,5 m de altura, con flores blanquecinas"; Solís Neffa \& Seijo 575 (CTES). Dpto. Patiño: Las Lomitas; 130 m.s.m; 11/12/1984; "2 m de altura. En bosque de "quebracho colorado"; Schinini \& Pire 24211(CTES). 15 km NW de Las Lomitas, camino a La Soledad; 130 m.sm; 12/12/1984; “Arbusto de 2 m de altura. En bosque xerófilo con abundancia de Carandá (Trithrinax. sp)"; Schinini \& Pire 24255 (CTES). Ibarreta; 01/06/1970; Martínez 154 (CTES). Bartolome de las Casas; 06/12/1972; "Flores blancas"; Maruñak et al. 440 (CTES). Dpto. Pilagá: Misión Tacaaglé; 18/11/1978; "Arbolito, ramoso, enmarañado, frutos maduros anaranjados"; Arenas 606 (CTES). Prov. La Pampa: Dpto. Realicó: Realicó; 09/01/1945; “2,5 m de altura. Flor verdosa”; Schulz 5919 (CTES). Prov. Salta: Dpto. Metán: Ruta 5, a 5km E de ruta 9; 27/01/2007; "3,5 m de altura, con frutos inmaduros verdes"; Paula-Souza 7995 (CTES, ESA). Dpto. Rivadavia: La Paz; 09/01/1984; "Flores amarillo-verdosas"; Arenas 2591 (CTES). Prov. Santa Fe: Dpto. General Obligado: Villa Ana, estero La Julia; 02/01/1973; Quarín 766 (CTES). La Reserva, Arroyo Las Garzas; 30/03/1975; "1,5 m de altura. Al borde del camino a la sombra de un algarrobo"; Quarín 3059 (CTES). Dpto. 9 de julio: Colonia El Dichoso; 10/11/1987; "Muy florecido"; Pire 2517 (CTES). Santa Margarita; 04/02/1985; "1,5 m de altura"; Fernández 7243 (UNR). Dpto. San Jerónimo: Arroyo Colastiné, 15 km S de Coronda, Ruta Nac. 11; 27/01/1971; "2 m de altura. Suelo salino"; Krapovickas \& Irigoyen 17784 (CTES). Dpto. Vera: Est. Las Gamas, 19 km W de Vera, ruta 36; 21/03/1990; "2 m de altura. Frutos Rojos. En borde del camino"; Krapovickas \& Vanni 43599 (CTES). Las Gamas; 08/10/1980; "3 m de altura"; Lewis \& Pire 2759 (UNR). Las Gamas; 17/12/1982; "3 m de altura”; Pire 4292 (UNR). Prov. Santiago del Estero: Dpto. Capital: Arraga, Estación Exp. Agropecuaria INTA; 21/04/1983; "Arbusto de 2,30 m de altura. Fruto anaranjado. En bosque de algarrobal"; Renolfi 303 (CTES). Dpto. Copo: Ruta 16, 6 km SE de Los Pirpintos; 01/11/1974; "2 m de altura. Flores blancoamarillentas"; Schinini et al. 10023 (CTES). Ruta 16, 15 km NW de Los Tigres; 150 m.s.m; 28/01/2007; “3 $\mathrm{m}$ de altura. Frutos anaranjados"; Paula-Souza 8052 (CTES, ESA). Dpto. Guasayán: Sierra de Guasayán, Ruta 64, km 76; 17/11/1994; "3 m de altura"; Krapovickas \& Cristóbal 46205 (CTES). Dpto. Moreno: 12 km de Yuchán; 01/01/1974; "2 m de altura"; Krapovickas \& Cristóbal 14501 (CTES). PARAGUAY. Dpto. Amambay: Estancia Carmen de la sierra, Potrero Lili; 22/10/1991; "2-3 m de altura, con flores blancas. En isla de bosque"; Soria 4770 (CTES, FCQ). Dpto. Boquerón: Paratodo; 08/12/1974; "2 m de altura. Crece en vegetacion achaparrada. Frutos naranjas"; Arenas 1092 (CTES, CTESN). Estancia Toro Mocho; 16/02/2006; "Arbolito espinoso enmarañado, flores verdosas, fruto maduro naranja. Orillas bosque seco. Suelo arenoso"; Peña-Chocarro \& De Egea 462 (CTES, BM). 54 km S de Madrejón (Parque Nacional Defensores del Chaco); 12/03/2005; "1 m de altura"; Fortunato 8738 (CTES, BAB). Parque Valle Natural, $8 \mathrm{~km}$ de Colonia Neuland; 13/03/2005; "2 $\mathrm{m}$ de altura. Flor anaranjada. En pastizal alterado; Fortunato 8778 (CTES, BAB). Col. Menno, 68 km NE de Filadelfia; 10/12/1992; "2 m de altura. En borde bosque de quebracho blanco y mistol”; Krapovickas \& Cristóbal 44298 (CTES). Dr. Pedro P. Peña, laguna a 14 km al W del pueblo; 11/10/1987; "2 m de altura. En bosque ribereño"; Spichiger 2206 (G). El Carmen; 13/10/1987; "Arbusto apoyante de 3,5 m de altura. En bosque ribereño"; Spichiger 2257 (G). Estación Experimental Isla Poí; 26/02/1991; "2 m de altura. En Quebrachal degradado con pastura implantada"; Vanni et al. 2363 (CTES). Filadelfia; 26/11/1982; "3,5 m de altura, con frutos naranjas"; Hahn 812 (MO). Pozo colorado; 29/11/1988; Caballero Marmori 1502 (CTES). Campamento Laguna Capitán; 12/09/1990; "Arbusto ramoso, follaje primaveral verde claro; flores blanquecinas. En salitrales"; Vanni et al. 2022 (CTES). Colonia Fernheim; 09/1981; Arenas 1787 (CTES, BA). Línea 9, Estancia Margarita; 25/10/1994; "2-3 m de altura, con flores verdosas. En borde de bosque xerófito"; Mereles \& Degen 5823 (CTES, FCQ). 


\section{Bol. Soc. Argent. Bot. 53 (4) 2018}

Estancia María Esther; 27/10/1994; "Arbusto sarmentoso, flores blancas. Borde de la Cañada Madrid"; Mereles \& Degen 5860 (CTES). Dpto. Pte. Hayes: a $28 \mathrm{~km}$ de Pozo colorado s/ ruta a Concepción; 17/09/1993; "Arbusto espinoso de 1-2 m de altura, con flores cremosas"; Degen \& Mereles 3013 (CTES, FCQ). Villa Hayes; 05/03/1984; "5 m de altura, con frutos naranjas"; Hahn 2176 (MO). Rio Verde; 02/03/1980; "En bosque bajo"; Caballero Marmori 609 (CTES). Teniente Martínez y alrededores; 28/11/2000; "Arbusto apoyante, en fruto. En borde del bosque xerófito"; Mereles et al. 8309 (CTES). Ruta Trans-Chaco; 14/03/1979; "2 m de altura”; Schinini \& Bordas 16579 (CTES).

\section{C. pallida var. discolor}

ARGENTINA. Prov. Catamarca: Dpto. Capayán: Sierra de Ambato (Falda E): Quebrada de San Jerónimo, unos 5 km al NW de Chumbicha; 19/02/1975; Hunziker et al. 22774 (CORD). Dpto. Capital: San Fernando del Valle de Catamarca; 10/1910; Castillón 14101 (LIL). Dpto. Fray Mamerto Esquiu: Pomancillo; 12/01/1940; Castellanos 33523 (LIL). Dpto. La Paz: El Quebracho; 07/12/1946; Brizuela 359 (LIL). Quirós; 11/11/1946; Malvárez 46 (LIL). La Perforadora; 11/12/1946; Brizuela 428 (LIL). Dpto. Valle Viejo: Comienzo de la Cuesta del Portezuelo; 14/06/1958; Morello \& Cuezzo s.n. (LIL). Prov. Salta: Dpto. Anta: 8 km de J.V. González, Camino a Metán; 06/05/1975; “Arbolito de 3 m de altura”; Krapovickas et al.28153 (CTES). Joaquín V. González; 09/02/1945; Krapovickas 1720(LIL). Joaquín V. González; 04/1959; Morello s.n. (LIL 504974). Cnel. Mollinedo; 15/01/1947; Malvárez 592 (LIL). Dpto. General M.M de Güemes: Cabeza de Buey; 14/02/1951. Meyer 17132(LIL). Yaquasmé, N de Güemes; 07/02/1957; De la Sota 1340 (LIL). Arroyo saladillo, Ruta 34; 03/01/1971; "2 m de altura"; Krapovickas 17427 (CTES). Dpto. La Candelaria: Alrededores de La Candelaria; 17/02/1962; Meyer et al. 2211 (LIL). Dpto. La Viña: Coronel Moldes; 1300 m.s.m; 25/01/2007; "Arbusto de 3 m de altura, flores crema, frutos inmaduros crema"; Paula-Souza 7839 (CTES, ESA). Dpto. Metán: Camino Río Piedras a Metán; 05/12/1965; Villa Carenzo 2707 (LIL). Dpto. Orán: Camino de Santa Rosa a Pichanal; 16/03/1972; Legname \& Cuezzo 9032 (LIL). Pichanal; 10/11/1913; Rodríguez 1096 (LIL). Embarcación; 20/12/1946; Malvárez 324 (LIL). Padre Lozano; 02/01/1947; Malvárez 427 (LIL). Senda Hachada; 06/01/1947; Malvárez 466 (LIL). Dpto. Rosario de la Frontera: Talayaco, 28 km al Este de R. de la Frontera, Ruta 34; 29/03/1975; “Arbolito de 4 m de altura, frutos anaranjados"; Krapovickas et al.28026 (CTES). Almirante Brown; 18/02/1947; O’Donell 5389 (LIL). Antilla a San Lorenzo; 14/01/1964; Cuezzo 3337 (LIL). Dpto. San Martín: Angostura, Campo Durán; 18/01/1957; De la Sota 1177 (LIL). Prov. Santiago del Estero: Dpto. Copo: Los Tigres; 03/01/1947; Luna 20 (LIL). Dpto. Río Hondo: Mansupa; 24/01/1949; Legname 147 (LIL). Dpto. Pellegrini: Cerro del Remate; 15/01/1928; Venturi 5774 (LIL). Cerro del Remate; 02/04/1989; “Arbusto 2 m de altura”; Schinini 15371 (CTES, CP). Prov. Tucumán: Dpto. Burruyacu: Río Urueña, Ruta 34; 23/03/1977; "5 m de altura, frutos amarillos"; Krapovickas \& Schinini 30506 (CTES). Gobernador Garmendia; 25/12/1958; Villa Carenzo 401 (LIL). Burruyacu; 15/12/1899; Stuckert 8026 (CORD). Dpto. Capital: San Miguel de Tucumán, viaducto El Saladillo; 10/11/1907; Lillo 7175 (LIL). San Miguel de Tucumán, dique El Cadillal; 17/11/1904; Lillo 3822 (LIL). Dpto. Graneros: El Zapallar; 11/02/1948; Sotelo 167 (LIL). Parador Campo Alegre; 08/12/1924; Schreiter 3504 (LIL). Dpto. Trancas: Tapia; 24/12/1911; Rodríguez 220 (LIL). Camino Tapia-Ticucho; 16/01/1955; De la Sota 55 (LIL). Vipos, Ruta 9; 16/01/1971; "Arbusto de 2 m de altura"; Krapovickas \& Cristóbal 17743 (CTES). BOLIVIA. Dpto. Tarija: Prov. Gran Chaco: A 58,1 km E de Villa Montes, rumbo a Paraguay; 332 m.s.m; 10/01/2005; "Árbol de 5 a 6 m de altura. En bosque chaqueño"; Seijo et al. 3396 (CTES). PARAGUAY. Dpto.Alto Paraguay: Mayor Pablo Lagerenza; 06/04/1978; "Arbusto $2 \mathrm{~m}$ de altura. En bosque abierto de quebrachos. Suelo Arenoso"; Schinini \& Bordas 14992 (CTES). Cerro León. Parque Nacional Defensores del Chaco; 03/10/1979; "Arbusto 3 m de altura. En selva de inundación"; Schinini \& Bordas 18026 (CTES). Dpto. Boquerón: General Eugenio A. Garay, Picada de la Muerte; 350-380 m.s.m; 09/05/1988; Charpin et al. 21493 (CTES, G). Teniente Ochoa; 11/12/1987; "2 m de altura"; Schinini \& Palacios 25561 (CTES). A 7 km NW de Nueva Asuncion; 12/12/1987; "Arbusto 2 m de altura, flores blancas. En una lomada. Suelo Arenoso"; Schinini \& Palacios 25693 (CTES). Ruta Trans-Chaco; 07/03/1979; "A Arbusto ramoso de 1,50 m de altura. En bosque abierto xerofítico. Frutos rojos"; Schinini 16458 (CTES). Teniente Enciso; 23/02/2006; "Arbusto 3 m de altura, con hojas pubescentes, fruto maduro anaranjado. En vegetación baja xerofítica. Suelo Arenoso, con pequeñas dunas"; Peña-Chocarro et al. 2538 (CTES, BM). 


\section{J. Asmus et al. - Identidad taxonómica de Celtis tala y Celtis pallida}

Material Suplementario - Tabla 1. Variables en estudio.

\begin{tabular}{|c|c|c|}
\hline Caracteres & Estados & Código \\
\hline \multicolumn{3}{|l|}{ Vegetativos } \\
\hline Altura Individuo & & Altura.m.l \\
\hline Diámetro Individuo & & Diámetro.m.I \\
\hline Corteza & Lisa(1)/Rugosa(2) & Corteza \\
\hline Color & $\begin{array}{l}\text { Marrón claro(1)/Marrón claro con manchas } \\
\text { negras(2)/Marrón claro blanquecino(3)/ } \\
\text { Marrón grisáceo(4)/Marrón rojizo(5) }\end{array}$ & Color \\
\hline Lenticelas & Abundantes(A-1)/Ausentes(NO-2)/Pocas(P-3) & Lenticelas \\
\hline Pilosidad Ramas Jóvenes & $\begin{array}{l}\text { Casi glabras(CG-1)/Glabras(G-2)/ } \\
\text { Muy pilosas(MP-3)/Pilosas(P-4) }\end{array}$ & Ramas.Jóvenes.Pilosidad \\
\hline Pilosidad Ramas Adultas & Casi glabras(CG-1)/Glabras(G-2)/Pilosas(P-3) & Ramas.Adultas.Pilosidad \\
\hline Modificaciones del cormo & $\begin{array}{l}\text { Ramas espinosas(1)/Espinas origen } \\
\text { estipular(2)/Espinas de origen estipular } \\
\text { y algunas ramas espinosas(3) }\end{array}$ & Modific.del cormo \\
\hline Longitud de entrenudos & & Entrenudos.Long \\
\hline Longitud de la hoja & & H.Long.Total \\
\hline Longitud de la lámina & & H.Long.Lám \\
\hline Ancho de la lámina & & H.Ancho.Lám \\
\hline Longitud del pecíolo & & H.Pec.Long \\
\hline Ancho del pecíolo & & H.Pec.Ancho \\
\hline Ángulo del ápice & & H.Ap.Angulo \\
\hline Forma de la hoja & Ovada(1)/Ovada-lanceolada(2) & Forma Hoja \\
\hline Margen del tercio inferior de la hoja & $\begin{array}{l}\text { Dentada(D-1)/Entera(E-2)//rregular(I)/ } \\
\text { Semi-crenada(SC-4) }\end{array}$ & Margen Hoja.Terc.Inf \\
\hline Margen del tercio medio de la hoja & $\begin{array}{l}\text { Dentada(D-1)/Entera(E-2)/Irregular(I)/ } \\
\text { Semi-crenada(SC-4) }\end{array}$ & Margen Hoja.Terc.Med \\
\hline Margen del tercio superior de la hoja & $\begin{array}{l}\text { Dentada(D-1)/Entera(E-2)/Irregular(I)/ } \\
\text { Semi-crenada(SC-4) }\end{array}$ & Margen Hoja.Terc.Sup \\
\hline $\begin{array}{l}\text { Número de prominencias en el } \\
\text { margen izquierdo }\end{array}$ & & M.H.Num.Prom.Iz \\
\hline $\begin{array}{l}\text { Número de prominencias en el } \\
\text { margen derecho }\end{array}$ & & M.H.Num.Prom.Der \\
\hline Contraste de la lámina (Haz-Envés) & Concolor(1)/Discolor(2) & Lam.Cont.Haz-Env \\
\hline Simetría de la hoja & Asimétrico (1)/Simétrico(S) & Simetría hoja \\
\hline Pilosidad del haz de la lámina & $\begin{array}{l}\text { Casi glabro(CG-1)/Escasamente } \\
\text { piloso(EP-2)/Moderadamente piloso } \\
\text { (Mod.P-3)/Muy Piloso (MP-4) }\end{array}$ & Pilosidad.Haz.Lám \\
\hline Pilosidad del haz de la nervadura & $\begin{array}{l}\text { Casi glabro(CG-1)/Escasamente } \\
\text { piloso(EP-2)/Moderadamente piloso } \\
\text { (Mod.P-3)/Muy Piloso (MP-4) }\end{array}$ & Pilosidad.Haz.Nerv \\
\hline Pilosidad del haz del pecíolo & Casi glabro(1)/Muy piloso(2)/Piloso(3) & \\
\hline Pilosidad del envés de la lámina & $\begin{array}{l}\text { Casi glabro(CG-1)/Densamente piloso(DP-2)/ } \\
\text { Escasamente piloso(EP-3)/Moderadamente } \\
\text { piloso (Mod.P-4)/Muy Piloso (MP-5) }\end{array}$ & Pilosidad.Envés.Lám \\
\hline Pilosidad del envés de la nervadura & $\begin{array}{l}\text { Casi glabro(CG-1)/Densamente piloso(DP-2)/ } \\
\text { Escasamente piloso(EP-3)/Moderadamente } \\
\text { piloso (Mod.P-4)/Muy Piloso (MP-5) }\end{array}$ & Pilosidad.Envés.Nerv \\
\hline Pilosidad del envés del pecíolo & Casi glabro(1)/Glabro(2)/Muy piloso(3)/Piloso(4) & \\
\hline Ápice de la lámina & Aguda(1)/Emarginada(2)/Mucronada(3)/Obtusa(4) & Ápice.Hoja \\
\hline Base de la lámina & Asimétrica(1)/Obtusa(2)/Redondeada(3) & Base.Hoja \\
\hline Número de nervaduras & & H.Nerv. $N^{\circ}$ \\
\hline
\end{tabular}


Bol. Soc. Argent. Bot. 53 (4) 2018

\begin{tabular}{|c|c|c|}
\hline Caracteres & $\begin{array}{r}\text { Estados } \\
\end{array}$ & Código \\
\hline $\begin{array}{l}\text { Ángulo entre nervadura principal y } \\
\text { secundarias }\end{array}$ & $\begin{array}{l}\text { Entre } 0^{\circ} \text { y } 45^{\circ}(1) / \text { entre } 45^{\circ} \text { y } \\
60^{\circ}(2) / \text { entre } 60^{\circ} \text { y } 90^{\circ}(3)\end{array}$ & Angulos entre nervs. \\
\hline Contraste entre lámina y nervadura & Contrastante(1)/No contrastante(2) & Contraste color lam-nerv \\
\hline Tamaño de domacios basales & Ausentes(1)/Grandes(2)/Pequeños(3) & Domacios tamaño bas. \\
\hline Tamaño de domacios medios & Ausentes(1)/Grandes(2)/Pequeños(3) & D.tamaño.Medios \\
\hline Tamaño de domacios superiores & Ausentes(1)/Pequeños(2) & D.tamaño.Superiores \\
\hline Número total de domacios & & D.N`total \\
\hline Número de domacios basales & & D.cantidad.basal \\
\hline Número de domacios medios & & D.cantidad.medio \\
\hline Número de domacios superiores & & D.cantidad.superior \\
\hline Tipo de domacios & $\begin{array}{l}\text { Ausentes(1)/Bolsillos muchos pelos(2)/ } \\
\text { Bolsillos pocos pelos(3) }\end{array}$ & D.Tipo \\
\hline \multicolumn{3}{|l|}{ Reproductivos } \\
\hline Largo del fruto & & Fruto.Largo.mm \\
\hline Ancho del fruto & & Fruto.Ancho.mm \\
\hline Largo del pireno & & Pireno.largo.mm \\
\hline Ancho del pireno & & Pireno.ancho.mm \\
\hline
\end{tabular}

Variables transformadas a variables auxiliares (dummy). 


\section{J. Asmus et al. - Identidad taxonómica de Celtis tala y Celtis pallida}

Material Suplementario - Tabla 2. Descripción de clusters para todas las variables

Grupo rojo: individuos pre identificados como C. pallida

\begin{tabular}{|c|c|c|c|c|c|c|}
\hline Variable_estado & v.test & $\begin{array}{l}\text { Media en } \\
\text { cluster }\end{array}$ & Media gral. & DS en cluster & DS gral. & $P$ valor \\
\hline Pilosidad.Pec.Envés_4 (piloso) & $4,854,509$ & 0.53125 & 0.17708333 & 0.35216962 & 0.28876909 & 1.21E-06 \\
\hline D.Tipo_2 (Bols muchos pelos) & $4,756,676$ & 0.86458333 & 0.35416667 & 0.24183722 & 0.42472673 & 1.97E-06 \\
\hline $\begin{array}{l}\text { Pilosidad.Envés. } \\
\text { Lam_3 (Esc. Piloso) }\end{array}$ & $4,405,826$ & 0.40104167 & 0.13151042 & 0.28465341 & 0.24214199 & $1.05 \mathrm{E}-05$ \\
\hline $\begin{array}{l}\text { Pilosidad.Envés. } \\
\text { Nerv_3 (Esc. Piloso) }\end{array}$ & $3,753,881$ & 0.390625 & 0.1640625 & 0.26408869 & 0.23888883 & $1.74 \mathrm{E}-04$ \\
\hline $\begin{array}{l}\text { Modific..del.cormo_1 (Ramas } \\
\text { espinosas. caulinar) }\end{array}$ & $3,345,217$ & 1 & 0.58333333 & 0 & 0.49300665 & 8.22E-04 \\
\hline Corteza_1 (Lisa) & $3,345,217$ & 1 & 0.58333333 & 0 & 0.49300665 & 8.22E-04 \\
\hline $\begin{array}{l}\text { Pilosidad.Envés.Nerv_4 } \\
\text { (Mod. Piloso) }\end{array}$ & $3,085,681$ & 0.28645833 & 0.10546875 & 0.33018533 & 0.23216186 & 2.03E-03 \\
\hline $\begin{array}{l}\text { Ramas.adultas. } \\
\text { Pilosidad_3 (Piloso) }\end{array}$ & $2,842,658$ & 0.58333333 & 0.29166667 & 0.39965263 & 0.40611643 & 4.47E-03 \\
\hline $\begin{array}{l}\text { Pilosidad.Haz.Nerv_2 } \\
\text { (Esc. Piloso) }\end{array}$ & $2,726,941$ & 0.3125 & 0.17057292 & 0.1692508 & 0.20600506 & $6.39 \mathrm{E}-03$ \\
\hline $\begin{array}{l}\text { Margen.Hoja.Terc. } \\
\text { Med_2 (Entero) }\end{array}$ & $2,600,553$ & 0.54166667 & 0.40625 & 0.14731391 & 0.20610791 & $9.31 \mathrm{E}-03$ \\
\hline Simetría.Hoja_2 (Simetrica) & $2,462,683$ & 0.16145833 & 0.10286458 & 0.10031959 & 0.09417403 & $1.38 \mathrm{E}-02$ \\
\hline $\begin{array}{l}\text { Contraste.Color.Lam. } \\
\text { Nerv_2. (No contrast) }\end{array}$ & $2,430,091$ & 0.86458333 & 0.6171875 & 0.22654753 & 0.4029564 & $1.51 \mathrm{E}-02$ \\
\hline $\begin{array}{l}\text { Ramas.jóvenes. } \\
\text { Pilosidad_3 (Muy piloso) }\end{array}$ & $2,346,359$ & 0.75 & 0.48046875 & 0.38188131 & 0.45467698 & $1.90 \mathrm{E}-02$ \\
\hline Lam.Cont.Haz.Env_1 (Concolor) & $2,124,486$ & 0.99479167 & 0.76953125 & 0.01727409 & 0.41968107 & 3.36E-02 \\
\hline $\begin{array}{l}\text { D.Tamaño.Superiores_1 } \\
\text { (Ausentes) }\end{array}$ & $2,038,243$ & 0.92708333 & 0.78776042 & 0.15694291 & 0.27055462 & 4.15E-02 \\
\hline Apice.Hoja_3 (Mucronada) & $1,991,426$ & 0.55208333 & 0.44661458 & 0.21924547 & 0.20962733 & 4.64E-02 \\
\hline $\begin{array}{l}\text { D.Tamaño.Superiores_2 } \\
\text { (Pequeños) }\end{array}$ & $-2,038,243$ & 0.07291667 & 0.21223958 & 0.15694291 & 0.27055462 & 4.15E-02 \\
\hline D.Cantidad.Superior & $-2,097,678$ & 0.09895833 & 0.359375 & 0.22310885 & 0.49138079 & 3.59E-02 \\
\hline $\begin{array}{l}\text { Pilosidad.Pec.Haz_1 } \\
\text { (Casi glabro) }\end{array}$ & $-2,148,694$ & 0.01041667 & 0.171875 & 0.03454818 & 0.29742274 & 3.17E-02 \\
\hline Lam.Cont.Haz.Env_2 (Discolor) & $-2,158,161$ & 0 & 0.22916667 & 0 & 0.42029669 & 3.09E-02 \\
\hline D.Tipo_1 (Ausentes) & $-2,214,191$ & 0.00520833 & 0.20052083 & 0.01727409 & 0.34914291 & 2.68E-02 \\
\hline $\begin{array}{l}\text { Domacios.Tamaño. } \\
\text { Bas_1 (Ausentes) }\end{array}$ & $-2,227,616$ & 0.01041667 & 0.20572917 & 0.02329238 & 0.3470388 & 2.59E-02 \\
\hline $\begin{array}{l}\text { Pilosidad.Envés.Nerv_2 } \\
\text { (Densamente piloso) }\end{array}$ & $-2,260,022$ & 0 & 0.22786458 & 0 & 0.39907314 & 2.38E-02 \\
\hline $\begin{array}{l}\text { Pilosidad.Envés.Nerv_2 } \\
\text { (Densamente piloso) }\end{array}$ & $-2,260,022$ & 0 & 0.22786458 & 0 & 0.39907314 & $2.38 \mathrm{E}-02$ \\
\hline $\begin{array}{l}\text { Pilosidad.Envés.Lam_2 } \\
\text { (Densamente piloso) }\end{array}$ & $-2,430,091$ & 0.13541667 & 0.3828125 & 0.22654753 & 0.4029564 & $2.38 \mathrm{E}-02$ \\
\hline $\begin{array}{l}\text { Contraste.Color.Lam. } \\
\text { Nerv_1. (Contrastante) }\end{array}$ & $-2,462,683$ & 0.83854167 & 0.89713542 & 0.10031959 & 0.09417403 & $1.51 \mathrm{E}-02$ \\
\hline Simetría.Hoja_1 (Asimétrica) & $-2,600,165$ & 0.13020833 & 0.4453125 & 0.24401472 & 0.47966884 & $1.38 \mathrm{E}-02$ \\
\hline $\begin{array}{l}\text { D..Tipo_3 (Bolsillos } \\
\text { pocos pelos) }\end{array}$ & $-2,600,869$ & $126,041,667$ & $209,114,583$ & 0.6311331 & $12,642,391$ & $9.32 \mathrm{E}-03$ \\
\hline
\end{tabular}




\begin{tabular}{|l|c|c|c|c|c|c|}
\hline \multicolumn{1}{|c|}{ Variable_estado } & v.test & $\begin{array}{c}\text { Media en } \\
\text { cluster }\end{array}$ & Media gral. & DS en cluster & DS gral. & P valor \\
\hline M.H.Num.Prom.der & $-2,614,047$ & $366,666,667$ & $43,671,875$ & 0.61784094 & $106,070,812$ & $9.30 \mathrm{E}-03$ \\
\hline H.Nerv.N. & $-2,630,695$ & 128,125 & $205,208,333$ & 0.61687426 & $115,978,719$ & $8.95 \mathrm{E}-03$ \\
\hline M.H.Num.Prom.iz & $-266,856$ & 0 & 0.3125 & 0 & 0.46351241 & $8.52 \mathrm{E}-03$ \\
\hline $\begin{array}{l}\text { Modific.del.cormo_2 } \\
\text { (Espinas orig. Estip.) }\end{array}$ & $-2,813,777$ & $166,666,667$ & 451,125 & 0.74311656 & $400,144,954$ & $7.62 \mathrm{E}-03$ \\
\hline Altura.m.I & $-2,861,189$ & 0.06385417 & 0.07664063 & 0.0076113 & 0.01768854 & $4.90 \mathrm{E}-03$ \\
\hline H.Pec.Ancho & $-3,029,854$ & $199,895,833$ & $259,914,062$ & 0.24714468 & 0.78406076 & $4.22 \mathrm{E}-03$ \\
\hline H.long.lám & $-3,077,747$ & $11,221,875$ & $142,269,531$ & 0.23425796 & 0.38646592 & $2.45 \mathrm{E}-03$ \\
\hline H.ancho.lám & $-3,118,731$ & $21,909,375$ & $290,727,865$ & 0.24932337 & 0.90913901 & $2.09 \mathrm{E}-03$ \\
\hline H.long.total. & $-3,175,031$ & 0.0059375 & 0.14406771 & 0.01451584 & 0.17219837 & $1.82 \mathrm{E}-03$ \\
\hline Diámetro.m.I & $-3,345,217$ & 0 & 0.41666667 & 0 & 0.49300665 & $1.50 \mathrm{E}-03$ \\
\hline Corteza_2 (Rugosa) & $-3,480,573$ & 0.08333333 & 0.48958333 & 0.2763854 & 0.46198827 & $8.22 \mathrm{E}-04$ \\
\hline $\begin{array}{l}\text { Ramas.adultas. } \\
\text { Pilosidad_2 (Glabro) }\end{array}$ & $-3,536,506$ & 0.23182292 & 0.35505208 & 0.04109065 & 0.13792004 & $5.00 \mathrm{E}-04$ \\
\hline H.Pec.Long & $-3,536,506$ & 0.23182292 & 0.35505208 & 0.04109065 & 0.13792004 & $4.05 \mathrm{E}-04$ \\
\hline
\end{tabular}

Grupo azul: individuos pre identificados como C. tala

\begin{tabular}{|c|c|c|c|c|c|c|}
\hline Variable_estado & v.test & $\begin{array}{l}\text { Media en } \\
\text { cluster }\end{array}$ & Media gral. & $\begin{array}{l}\text { DS en } \\
\text { cluster }\end{array}$ & DS gral. & P valor \\
\hline Corteza_2 (Rugosa) & $6,855,655$ & 1 & 0.41666667 & 0 & 0.49300665 & $7.10 \mathrm{E}-12$ \\
\hline $\begin{array}{l}\text { D..Tipo_3 (bolsillo } \\
\text { con pocos pelos) }\end{array}$ & $6,587,018$ & 0.990625 & 0.4453125 & 0.0298106 & 0.47966884 & 4.49E-11 \\
\hline H.Pec.Long & $5,980,365$ & 0.4974062 & 0.35505208 & 0.07290332 & 0.13792004 & 2.23E-09 \\
\hline Altura.m.I & $5,848,097$ & 8.55 & 451,125 & $313,791,332$ & $400,144,954$ & 4.97E-09 \\
\hline Diámetro.m.I & $5,803,639$ & 0.31655 & 0.14406771 & 0.13499684 & 0.17219837 & $6.49 \mathrm{E}-09$ \\
\hline H.long.total. & $5,768,122$ & $38,123,438$ & $290,727,865$ & 0.5368182 & 0.90913901 & 8.02E-09 \\
\hline $\begin{array}{l}\text { Pilosidad.Envés. } \\
\text { Nerv_1 (Casi glabro) }\end{array}$ & $5,761,836$ & 0.809375 & 0.38932292 & 0.27984022 & 0.42240314 & 8.32E-09 \\
\hline H.long.lám & 563,487 & $33,616,563$ & $259,914,062$ & 0.48913657 & 0.78406076 & $1.75 \mathrm{E}-08$ \\
\hline Fruto.Largo.mm & $5,524,956$ & $78,322,812$ & $70,724,349$ & 0.28885065 & 0.79685965 & 3.30E-08 \\
\hline $\begin{array}{l}\text { Modific.del.cormo_2 } \\
\text { (Esp. Origen estip.) }\end{array}$ & 546,892 & 0.75 & 0.3125 & 0.4330127 & 0.46351241 & 4.53E-08 \\
\hline $\begin{array}{l}\text { Pilosidad.Envés. } \\
\text { Lam_1(Casi glabro) }\end{array}$ & $5,457,246$ & 0.89375 & 0.46354167 & 0.2508579 & 0.45676222 & 4.84E-08 \\
\hline $\begin{array}{l}\text { D.Tamaño.Medios_3 } \\
\text { (Pequeños) }\end{array}$ & $5,431,655$ & 0.803125 & 0.4609375 & 0.20085267 & 0.3650202 & $5.58 \mathrm{E}-08$ \\
\hline Apice.Hoja_1 (Aguda) & $5,360,202$ & 0.525 & 0.2890625 & 0.15360257 & 0.25503555 & 8.31E-08 \\
\hline $\begin{array}{l}\text { Pilosidad.Haz. } \\
\text { Nerv_1(Casi glabro) }\end{array}$ & 534,161 & 0.91875 & 0.51171875 & 0.20358122 & 0.44150994 & $9.21 \mathrm{E}-08$ \\
\hline $\begin{array}{l}\text { Pilosidad.Haz.Lam_1 } \\
\text { (Casi glabro) }\end{array}$ & $5,288,667$ & 0.95625 & 0.54557292 & 0.11875 & 0.44992396 & $1.23 \mathrm{E}-07$ \\
\hline Pireno.Largo.mm & $5,273,844$ & $58,931,562$ & $531,832,031$ & 0.24143091 & 0.631541 & $1.34 \mathrm{E}-07$ \\
\hline $\begin{array}{l}\text { Contraste.Color.Lam. } \\
\text { Nerv_1. (Contrastante) }\end{array}$ & $5,234,833$ & 0.746875 & 0.3828125 & 0.29413207 & 0.4029564 & $1.65 \mathrm{E}-07$ \\
\hline
\end{tabular}




\begin{tabular}{|c|c|c|c|c|c|c|}
\hline Variable_estado & v.test & $\begin{array}{l}\text { Media en } \\
\text { cluster }\end{array}$ & Media gral. & $\begin{array}{l}\text { DS en } \\
\text { cluster }\end{array}$ & DS gral. & $P$ valor \\
\hline $\begin{array}{l}\text { D.Tamaño.Superiores_2 } \\
\text { (Grandes) }\end{array}$ & $5,158,702$ & 0.453125 & 0.21223958 & 0.23952671 & 0.27055462 & $2.49 \mathrm{E}-07$ \\
\hline D.N.total & 509,929 & $7,228,125$ & $411,588,542$ & $330,431,034$ & $353,629,317$ & $3.41 \mathrm{E}-07$ \\
\hline D.Cantidad.Medio & $5,090,333$ & $2,496,875$ & $126,953,125$ & $133,016,021$ & $139,702,741$ & 3.57E-07 \\
\hline D.Cantidad.Superior & $5,048,209$ & 0.7875 & 0.359375 & 0.47819648 & 0.49138079 & 4.46E-07 \\
\hline $\begin{array}{l}\text { Pilosidad.Pec.Envés_1 } \\
\text { (Casi glabro) }\end{array}$ & $4,910,844$ & 0.73125 & 0.37109375 & 0.37348653 & 0.42493226 & 9.07E-07 \\
\hline $\begin{array}{l}\text { Ramas.adultas. } \\
\text { Pilosidad_2 (Glabras) }\end{array}$ & $4,833,753$ & 0.875 & 0.48958333 & 0.26809513 & 0.46198827 & 1.34E-06 \\
\hline H.Pec.Ancho & $4,724,051$ & 0.0910625 & 0.07664063 & 0.01555497 & 0.01768854 & $2.31 \mathrm{E}-06$ \\
\hline D.Cantidad.Basal & $4,649,801$ & 3.95 & $249,088,542$ & $174,660,385$ & $181,819,282$ & 3.32E-06 \\
\hline $\begin{array}{l}\text { Pilosidad.Pec.Haz_1 } \\
\text { (Casi glabro) }\end{array}$ & $4,504,976$ & 0.403125 & 0.171875 & 0.34600115 & 0.29742274 & 6.64E-06 \\
\hline Fruto.Ancho.mm & 422,232 & $62,350,937$ & $58,677,474$ & 0.263399 & 0.50409162 & $2.42 \mathrm{E}-05$ \\
\hline Pireno.Ancho.mm & $3,994,071$ & $47,368,438$ & $450,914,062$ & 0.13436591 & 0.33032247 & $6.49 \mathrm{E}-05$ \\
\hline $\begin{array}{l}\text { Pilosidad.Pec. } \\
\text { Haz_3 (Piloso) }\end{array}$ & $3,650,433$ & 0.59375 & 0.35807292 & 0.34261175 & 0.37407429 & 2.62E-04 \\
\hline H.ancho.lám & $3,552,165$ & $1,659,625$ & $142,269,531$ & 0.28071981 & 0.38646592 & $3.82 \mathrm{E}-04$ \\
\hline $\begin{array}{l}\text { Forma.Hoja_2 (Ovada- } \\
\text { lanceolada) }\end{array}$ & $3,441,294$ & 0.8375 & 0.65755208 & 0.1457738 & 0.30297719 & $5.79 \mathrm{E}-04$ \\
\hline $\begin{array}{l}\text { Domacios.Tamaño. } \\
\text { Bas_2 (Garndes) }\end{array}$ & $3,375,329$ & 0.45 & 0.26302083 & 0.3460717 & 0.32096816 & 7.37E-04 \\
\hline Lenticelas_3 (Pocas) & $3,306,765$ & 0.55 & 0.3125 & 0.44440972 & 0.41614551 & $9.44 \mathrm{E}-04$ \\
\hline $\begin{array}{l}\text { Ramas.jóvenes. } \\
\text { Pilosidad_4 (Pilosas) }\end{array}$ & 329,531 & 0.575 & 0.33333333 & 0.45483513 & 0.42491829 & $9.83 \mathrm{E}-04$ \\
\hline $\begin{array}{l}\text { Lam.Cont.Haz. } \\
\text { Env_1 (Concolor) }\end{array}$ & $3,181,834$ & 1 & 0.76953125 & 0 & 0.41968107 & 1.46E-03 \\
\hline $\begin{array}{l}\text { Pilosidad.Pec. } \\
\text { Envés_2 (Glabro) }\end{array}$ & $2,918,383$ & 0.2375 & 0.09895833 & 0.38557992 & 0.27505721 & 3.52E-03 \\
\hline $\begin{array}{l}\text { Margen.Hoja.Terc. } \\
\text { Sup_2 (Entero) }\end{array}$ & $2,871,163$ & 0.34375 & 0.23567708 & 0.2240431 & 0.2180941 & 4.09E-03 \\
\hline $\begin{array}{l}\text { Modific.del.cormo_3 esp. } \\
\text { orig fol.yramasesp) }\end{array}$ & $2,766,074$ & 0.25 & 0.10416667 & 0.4330127 & 0.30547663 & 5.67E-03 \\
\hline $\begin{array}{l}\text { Ramas.jóvenes. } \\
\text { Pilosidad_1(Casi glabro) }\end{array}$ & $2,600,487$ & 0.225 & 0.10416667 & 0.36996621 & 0.269226 & $9.31 \mathrm{E}-03$ \\
\hline $\begin{array}{l}\text { Margen.Hoja.Terc. } \\
\text { Inf_2 (Entero) }\end{array}$ & $2,266,058$ & 0.959375 & 0.90494792 & 0.07201074 & 0.13916463 & $2.34 \mathrm{E}-02$ \\
\hline $\begin{array}{l}\text { Apice.Hoja_2 } \\
\text { (Emarginada) }\end{array}$ & $-2,050,145$ & 0.0125 & 0.0390625 & 0.025 & 0.0750705 & 4.04E-02 \\
\hline $\begin{array}{l}\text { Pilosidad.Envés. } \\
\text { Lam_5(Muy piloso) }\end{array}$ & $-2,086,499$ & 0 & 0.07161458 & 0 & 0.19886952 & 3.69E-02 \\
\hline $\begin{array}{l}\text { Pilosidad.Envés. } \\
\text { Nerv_5(Muy piloso) }\end{array}$ & $-2,563,901$ & 0 & 0.11328125 & 0 & 0.25600097 & $1.04 \mathrm{E}-02$ \\
\hline $\begin{array}{l}\text { Margen.Hoja.Terc. } \\
\text { Med_4(irregular) }\end{array}$ & $-2,635,124$ & 0.00625 & 0.0859375 & 0.02724312 & 0.17521611 & $8.41 \mathrm{E}-03$ \\
\hline Apice.Hoja_3(mucronado) & $-2,670,421$ & 0.35 & 0.44661458 & 0.1548689 & 0.20962733 & $7.58 \mathrm{E}-03$ \\
\hline
\end{tabular}


Bol. Soc. Argent. Bot. 53 (4) 2018

\begin{tabular}{|c|c|c|c|c|c|c|}
\hline Variable_estado & v.test & $\begin{array}{l}\text { Media en } \\
\text { cluster }\end{array}$ & Media gral. & $\begin{array}{l}\text { DS en } \\
\text { cluster }\end{array}$ & DS gral. & $\mathrm{P}$ valor \\
\hline $\begin{array}{l}\text { Pilosidad.Pec. } \\
\text { Envés_4(Piloso) }\end{array}$ & $-2,926,112$ & 0.03125 & 0.17708333 & 0.07525997 & 0.28876909 & $3.43 \mathrm{E}-03$ \\
\hline $\begin{array}{l}\text { Margen.Hoja.Terc. } \\
\text { Sup_4(Semi-crenado) }\end{array}$ & $-3,031,053$ & 0.003125 & 0.10546875 & 0.01362156 & 0.19563775 & $2.44 \mathrm{E}-03$ \\
\hline $\begin{array}{l}\text { Pilosidad.Haz. } \\
\text { Nerv_2(Escas. piloso) }\end{array}$ & $-3,039,652$ & 0.0625 & 0.17057292 & 0.14388581 & 0.20600506 & 2.37E-03 \\
\hline $\begin{array}{l}\text { Domacios.Tamaño. } \\
\text { Bas_1(Ausentes) }\end{array}$ & $-3,121,764$ & 0.01875 & 0.20572917 & 0.04463393 & 0.3470388 & $1.80 \mathrm{E}-03$ \\
\hline $\begin{array}{l}\text { Lam.Cont.Haz. } \\
\text { Env_2(discolor) }\end{array}$ & $-3,159,224$ & 0 & 0.22916667 & 0 & 0.42029669 & $1.58 \mathrm{E}-03$ \\
\hline D..Tipo_1(Ausentes) & $-3,172,097$ & 0.009375 & 0.20052083 & 0.0298106 & 0.34914291 & $1.51 \mathrm{E}-03$ \\
\hline $\begin{array}{l}\text { Pilosidad.Envés. } \\
\text { Nerv_2(Densamente } \\
\text { piloso) }\end{array}$ & $-3,308,333$ & 0 & 0.22786458 & 0 & 0.39907314 & $9.39 \mathrm{E}-04$ \\
\hline $\begin{array}{l}\text { Pilosidad.Envés. } \\
\text { Lam_2(Densamente } \\
\text { piloso) }\end{array}$ & $-3,308,333$ & 0 & 0.22786458 & 0 & 0.39907314 & $9.39 \mathrm{E}-04$ \\
\hline $\begin{array}{l}\text { Pilosidad.Haz. } \\
\text { Lam_2(Escas. piloso) }\end{array}$ & $-3,374,975$ & 0.04375 & 0.1796875 & 0.11875 & 0.2333746 & 7.38E-04 \\
\hline Forma.Hoja_1(ovada) & $-3,441,294$ & 0.1625 & 0.34244792 & 0.1457738 & 0.30297719 & $5.79 \mathrm{E}-04$ \\
\hline Apice.Hoja_4(obtusa) & $-358,781$ & 0.1125 & 0.22526042 & 0.08970438 & 0.1821009 & 3.33E-04 \\
\hline $\begin{array}{l}\text { Ramas.adultas. } \\
\text { Pilosidad_3(Piloso) }\end{array}$ & $-3,804,548$ & 0.025 & 0.29166667 & 0.10897247 & 0.40611643 & $1.42 \mathrm{E}-04$ \\
\hline Lenticelas_1(Abundantes) & $-3,906,372$ & 0.25 & 0.5625 & 0.40311289 & 0.46351241 & 9.37E-05 \\
\hline $\begin{array}{l}\text { Pilosidad.Haz. } \\
\text { Lam_3(Mod. piloso) }\end{array}$ & $-4,235,803$ & 0 & 0.26953125 & 0 & 0.36868737 & $2.28 \mathrm{E}-05$ \\
\hline $\begin{array}{l}\text { Pilosidad.Haz. } \\
\text { Nerv_3(Mod. piloso) }\end{array}$ & $-4,346,574$ & 0.01875 & 0.3046875 & 0.08172936 & 0.38116141 & $1.38 \mathrm{E}-05$ \\
\hline $\begin{array}{l}\text { Pilosidad.Pec. } \\
\text { Envés_3(Muy piloso) }\end{array}$ & $-4,658,396$ & 0 & 0.35286458 & 0 & 0.43889094 & 3.19E-06 \\
\hline $\begin{array}{l}\text { D..Tipo_2 (Bols. Con } \\
\text { muchos pelos) }\end{array}$ & $-4,831,511$ & 0 & 0.35416667 & 0 & 0.42472673 & 1.36E-06 \\
\hline H.Pec.Angulo & $-4,928,017$ & $713,064,687$ & $953,638,412$ & $135,164,033$ & $28,285,307$ & 8.31E-07 \\
\hline $\begin{array}{l}\text { D.Tamaño.Superiores_1 } \\
\text { (Ausentes) }\end{array}$ & $-5,158,702$ & 0.546875 & 0.78776042 & 0.23952671 & 0.27055462 & 2.49E-07 \\
\hline $\begin{array}{l}\text { Contraste.Color.Lam. } \\
\text { Nerv_2. (No contrast) }\end{array}$ & $-5,234,833$ & 0.253125 & 0.6171875 & 0.29413207 & 0.4029564 & $1.65 \mathrm{E}-07$ \\
\hline $\begin{array}{l}\text { Ramas.jóvenes. } \\
\text { Pilosidad_3 (Piloso) }\end{array}$ & $-5,485,593$ & 0.05 & 0.48046875 & 0.15 & 0.45467698 & 4.12E-08 \\
\hline $\begin{array}{l}\text { D.Tamaño.Medios_1 } \\
\text { (Ausentes) }\end{array}$ & $-5,580,277$ & 0.184375 & 0.53255208 & 0.16709255 & 0.36151752 & $2.40 \mathrm{E}-08$ \\
\hline $\begin{array}{l}\text { Pilosidad.Pec.Haz_2 } \\
\text { (Muy piloso) }\end{array}$ & $-5,911,151$ & 0.003125 & 0.47005208 & 0.01362156 & 0.45767998 & 3.40E-09 \\
\hline $\begin{array}{l}\text { Modific.del.cormo_1 } \\
\text { (Ramas espinosas) }\end{array}$ & $-6,855,655$ & 0 & 0.58333333 & 0 & 0.49300665 & 7.10E-12 \\
\hline Corteza_1 (lisa) & $-6,855,655$ & 0 & 0.58333333 & 0 & 0.49300665 & 7.10E-12 \\
\hline
\end{tabular}




\section{J. Asmus et al. - Identidad taxonómica de Celtis tala y Celtis pallida}

Grupo verde: individuos pre identificados como C. pallida

\begin{tabular}{|c|c|c|c|c|c|c|}
\hline Variable_estado & v.test & $\begin{array}{l}\text { Media en } \\
\text { cluster }\end{array}$ & Media gral. & $\begin{array}{l}\text { DS en } \\
\text { cluster }\end{array}$ & DS gral. & P valor \\
\hline $\begin{array}{l}\text { Pilosidad.Pec. } \\
\text { Envés_3(Muy piloso) }\end{array}$ & $5,982,868$ & 0.89453125 & 0.35286458 & 0.17776657 & 0.43889094 & 2.19E-09 \\
\hline $\begin{array}{l}\text { Pilosidad.Envés. } \\
\text { Nerv_2(Dens. piloso) }\end{array}$ & 55,359 & 0.68359375 & 0.22786458 & 0.40773092 & 0.39907314 & $3.10 \mathrm{E}-08$ \\
\hline $\begin{array}{l}\text { Pilosidad.Envés. } \\
\text { Lam_2(Dens. piloso) }\end{array}$ & 55,359 & 0.68359375 & 0.22786458 & 0.40773092 & 0.39907314 & $3.10 \mathrm{E}-08$ \\
\hline $\begin{array}{l}\text { Pilosidad.Haz. } \\
\text { Nerv_3(Moder. piloso) }\end{array}$ & $5,514,524$ & 0.73828125 & 0.3046875 & 0.24923589 & 0.38116141 & $3.50 \mathrm{E}-08$ \\
\hline D.Tipo_1 (Ausentes) & $5,351,323$ & 0.5859375 & 0.20052083 & 0.37621872 & 0.34914291 & 8.73E-08 \\
\hline $\begin{array}{l}\text { Domacios.Tamaño. } \\
\text { Bas_1 (Ausentes) }\end{array}$ & $5,311,015$ & 0.5859375 & 0.20572917 & 0.37621872 & 0.3470388 & $1.09 \mathrm{E}-07$ \\
\hline $\begin{array}{l}\text { Lam.Cont.Haz. } \\
\text { Env_2(Discolor) }\end{array}$ & $5,286,393$ & 0.6875 & 0.22916667 & 0.46351241 & 0.42029669 & $1.25 \mathrm{E}-07$ \\
\hline $\begin{array}{l}\text { Pilosidad.Haz. } \\
\text { Lam_3(Moder. piloso) }\end{array}$ & $5,136,126$ & 0.66015625 & 0.26953125 & 0.30775202 & 0.36868737 & $2.80 \mathrm{E}-07$ \\
\hline $\begin{array}{l}\text { Pilosidad.Pec. } \\
\text { Haz_2(Muy piloso) }\end{array}$ & 495,114 & 0.9375 & 0.47005208 & 0.125 & 0.45767998 & 7.38E-07 \\
\hline $\begin{array}{l}\text { D.Tamaño.Medios_1 } \\
\text { (Ausentes) }\end{array}$ & 485,387 & 0.89453125 & 0.53255208 & 0.16494369 & 0.36151752 & $1.21 \mathrm{E}-06$ \\
\hline $\begin{array}{l}\text { Margen.Hoja.Terc. } \\
\text { Sup_4(semi-crenado) }\end{array}$ & $4,452,451$ & 0.28515625 & 0.10546875 & 0.25094426 & 0.19563775 & 8.49E-06 \\
\hline H.Pec.Angulo & $4,202,072$ & $119,882,148$ & $953,638,411$ & $190,666,434$ & $28,285,307$ & 2.64E-05 \\
\hline M.H.Num.Prom.iz & $4,125,377$ & $30,390,625$ & $205,208,333$ & 0.86627204 & $115,978,719$ & 3.70E-05 \\
\hline $\begin{array}{l}\text { Margen.Hoja.Terc. } \\
\text { Med_4(semi-crenado) }\end{array}$ & 41,068 & 0.234375 & 0.0859375 & 0.23952671 & 0.17521611 & 4.01E-05 \\
\hline $\begin{array}{l}\text { Modific.del.cormo_1(Ramas } \\
\text { esp.orig.caul) }\end{array}$ & $4,097,037$ & 1 & 0.58333333 & 0 & 0.49300665 & 4.18E-05 \\
\hline Corteza_1 (Lisa) & $4,097,037$ & 1 & 0.58333333 & 0 & 0.49300665 & 4.18E-05 \\
\hline Forma.Hoja_1(Ovada) & 402,087 & 0.59375 & 0.34244792 & 0.31093357 & 0.30297719 & $5.80 \mathrm{E}-05$ \\
\hline M.H.Num.Prom.der & $3,904,364$ & $3,109,375$ & $209,114,583$ & 0.95950732 & $12,642,391$ & $9.45 \mathrm{E}-05$ \\
\hline Apice.Hoja_4 (obtusa) & $3,778,219$ & 0.3671875 & 0.22526042 & 0.20714177 & 0.1821009 & $1.58 \mathrm{E}-04$ \\
\hline $\begin{array}{l}\text { Ramas.jóvenes. } \\
\text { Pilosidad_3(Muy piloso) }\end{array}$ & $3,581,702$ & 0.81640625 & 0.48046875 & 0.28935268 & 0.45467698 & $3.41 \mathrm{E}-04$ \\
\hline $\begin{array}{l}\text { D.Tamaño.Superiores_1 } \\
\text { (Ausentes) }\end{array}$ & $3,522,854$ & 0.984375 & 0.78776042 & 0.06051536 & 0.27055462 & 4.27E-04 \\
\hline H.Nerv.N. & $3,427,672$ & $51,171,875$ & $43,671,875$ & 0.52564832 & $106,070,812$ & $6.09 \mathrm{E}-04$ \\
\hline $\begin{array}{l}\text { Contraste.Color.Lam. } \\
\text { Nerv_2.(No contrast.) }\end{array}$ & $3,242,537$ & 0.88671875 & 0.6171875 & 0.23719012 & 0.4029564 & $1.18 \mathrm{E}-03$ \\
\hline $\begin{array}{l}\text { Margen.Hoja.Terc. } \\
\text { Inf_1(Dentado) }\end{array}$ & $2,767,076$ & 0.09375 & 0.04947917 & 0.09375 & 0.07755871 & $5.66 \mathrm{E}-03$ \\
\hline $\begin{array}{l}\text { Pilosidad.Envés. } \\
\text { Nerv_5(Muy piloso) }\end{array}$ & 26,629 & 0.25390625 & 0.11328125 & 0.31519831 & 0.25600097 & $7.75 \mathrm{E}-03$ \\
\hline Lenticelas_1(Abundantes) & $2,614,644$ & 0.8125 & 0.5625 & 0.29973947 & 0.46351241 & 8.93E-03 \\
\hline $\begin{array}{l}\text { Margen.Hoja.Terc. } \\
\text { Inf_4(semi-crenado) }\end{array}$ & $2,495,967$ & 0.07421875 & 0.02473958 & 0.15502449 & 0.09609869 & $1.26 \mathrm{E}-02$ \\
\hline
\end{tabular}




\begin{tabular}{|c|c|c|c|c|c|c|}
\hline Variable_estado & v.test & $\begin{array}{l}\text { Media en } \\
\text { cluster }\end{array}$ & Media gral. & $\begin{array}{l}\text { DS en } \\
\text { cluster }\end{array}$ & DS gral. & P valor \\
\hline $\begin{array}{l}\text { Pilosidad.Haz. } \\
\text { Lam_2(Esc.piloso) }\end{array}$ & 243,423 & 0.296875 & 0.1796875 & 0.28081564 & 0.2333746 & 1.49E-02 \\
\hline $\begin{array}{l}\text { Pilosidad.Haz. } \\
\text { Lam_4(Muy piloso) }\end{array}$ & 235,147 & 0.015625 & 0.00520833 & 0.03493856 & 0.02147451 & 1.87E-02 \\
\hline Entrenudos.Long & $2,318,487$ & $2,421,875$ & $227,669,271$ & 0.35999268 & 0.30355891 & 2.04E-02 \\
\hline Apice.Hoja_2(Emarginada) & $2,270,216$ & 0.07421875 & 0.0390625 & 0.10178761 & 0.0750705 & 2.32E-02 \\
\hline $\begin{array}{l}\text { Pilosidad.Haz. } \\
\text { Nerv_4(Muy piloso) }\end{array}$ & $2,214,961$ & 0.0390625 & 0.01302083 & 0.09342391 & 0.05699497 & $2.68 \mathrm{E}-02$ \\
\hline $\begin{array}{l}\text { Pilosidad.Envés. } \\
\text { Lam_5(Muy piloso) }\end{array}$ & $1,967,869$ & 0.15234375 & 0.07161458 & 0.21982854 & 0.19886952 & $4.91 \mathrm{E}-02$ \\
\hline H.Pec.Ancho & $-2,312,361$ & 0.06820313 & 0.07664063 & 0.01178808 & 0.01768854 & $2.08 \mathrm{E}-02$ \\
\hline $\begin{array}{l}\text { Ramas.jóvenes. } \\
\text { Pilosidad_4(Piloso) }\end{array}$ & $-2,376,771$ & 0.125 & 0.33333333 & 0.21650635 & 0.42491829 & $1.75 \mathrm{E}-02$ \\
\hline $\begin{array}{l}\text { Pilosidad.Envés. } \\
\text { Lam_3(Escas. piloso) }\end{array}$ & $-2,476,431$ & 0.0078125 & 0.13151042 & 0.02066993 & 0.24214199 & 1.33E-02 \\
\hline Lenticelas_3 (Pocas) & $-2,548,219$ & 0.09375 & 0.3125 & 0.19515619 & 0.41614551 & $1.08 \mathrm{E}-02$ \\
\hline $\begin{array}{l}\text { Pilosidad.Pec.Haz_1 } \\
\text { (Casi glabro) }\end{array}$ & $-2,737,715$ & 0.00390625 & 0.171875 & 0.01512884 & 0.29742274 & $6.19 \mathrm{E}-03$ \\
\hline H.Pec.Long & $-3,005,927$ & 0.26953125 & 0.35505208 & 0.07156881 & 0.13792004 & $2.65 \mathrm{E}-03$ \\
\hline Pireno.Ancho.mm & $-3,096,207$ & $429,816,406$ & $450,914,063$ & 0.32479339 & 0.33032247 & $1.96 \mathrm{E}-03$ \\
\hline H.long.lám & $-310,999$ & $209,613,281$ & $259,914,063$ & 0.49940635 & 0.78406076 & 1.87E-03 \\
\hline $\begin{array}{l}\text { Margen.Hoja.Terc. } \\
\text { Med_2(Entero) }\end{array}$ & $-3,123,764$ & 0.2734375 & 0.40625 & 0.20595979 & 0.20610791 & $1.79 \mathrm{E}-03$ \\
\hline Diámetro.m.I & $-3,153,139$ & 0.0320625 & 0.14406771 & 0.04445007 & 0.17219837 & $1.62 \mathrm{E}-03$ \\
\hline H.long.total. & $-3,167,709$ & $231,320,312$ & $290,727,865$ & 0.55771826 & 0.90913901 & $1.54 \mathrm{E}-03$ \\
\hline $\begin{array}{l}\text { Pilosidad.Envés. } \\
\text { Nerv_3(Escas. piloso) }\end{array}$ & $-3,170,722$ & 0.0078125 & 0.1640625 & 0.02066993 & 0.23888883 & $1.52 \mathrm{E}-03$ \\
\hline $\begin{array}{l}\text { Contraste.Color.Lam. } \\
\text { Nerv_1.(Contrastante) }\end{array}$ & $-3,242,537$ & 0.11328125 & 0.3828125 & 0.23719012 & 0.4029564 & $1.18 \mathrm{E}-03$ \\
\hline $\begin{array}{l}\text { Modific. del.cormo_2 } \\
\text { (Espinas orig.estip.) }\end{array}$ & $-3,268,305$ & 0 & 0.3125 & 0 & 0.46351241 & $1.08 \mathrm{E}-03$ \\
\hline D.Cantidad.Superior & $-3,352,703$ & 0.01953125 & 0.359375 & 0.07564421 & 0.49138079 & 8.00E-04 \\
\hline $\begin{array}{l}\text { Margen.Hoja.Terc. } \\
\text { Inf_2(Entero) }\end{array}$ & $-3,356,414$ & 0.80859375 & 0.90494792 & 0.18150406 & 0.13916463 & 7.90E-04 \\
\hline Fruto.Ancho.mm & $-3,464,754$ & $550,746,094$ & $58,677,474$ & 0.47396631 & 0.50409162 & $5.31 \mathrm{E}-04$ \\
\hline $\begin{array}{l}\text { D.Tamaño.Superiores_2 } \\
\text { (Grandes) }\end{array}$ & $-3,522,854$ & 0.015625 & 0.21223958 & 0.06051536 & 0.27055462 & 4.27E-04 \\
\hline Altura.m.I & $-3,531,467$ & 159,625 & 451,125 & 0.59762943 & $400,144,954$ & 4.13E-04 \\
\hline D.Cantidad.Medio & $-3,551,324$ & 0.24609375 & $126,953,125$ & 0.48081796 & $139,702,741$ & 3.83E-04 \\
\hline $\begin{array}{l}\text { Domacios.Tamaño. } \\
\text { Bas_2 (Grandes) }\end{array}$ & $-3,854,489$ & 0.0078125 & 0.26302083 & 0.03025768 & 0.32096816 & 1.16E-04 \\
\hline Pilosidad.Pec..Haz_3 (Piloso) & $-3,880,991$ & 0.05859375 & 0.35807292 & 0.12395806 & 0.37407429 & $1.04 \mathrm{E}-04$ \\
\hline $\begin{array}{l}\text { Forma.Hoja_2(Ovada- } \\
\text { lanceolada) }\end{array}$ & $-402,087$ & 0.40625 & 0.65755208 & 0.31093357 & 0.30297719 & $5.80 \mathrm{E}-05$ \\
\hline Pireno.Largo.mm & $-4,046,068$ & $479,121,094$ & $531,832,031$ & 0.43356886 & 0.631541 & $5.21 \mathrm{E}-05$ \\
\hline
\end{tabular}


J. Asmus et al. - Identidad taxonómica de Celtis tala y Celtis pallida

\begin{tabular}{|l|c|c|c|c|c|c|}
\hline \multicolumn{1}{|c|}{ Variable_estado } & v.test & $\begin{array}{c}\text { Media en } \\
\text { cluster }\end{array}$ & Media gral. & $\begin{array}{c}\text { DS en } \\
\text { cluster }\end{array}$ & DS gral. & P valor \\
\hline Corteza_2 (Rugosa) & $-4,097,037$ & 0 & 0.41666667 & 0 & 0.49300665 & $4.18 \mathrm{E}-05$ \\
\hline $\begin{array}{l}\text { Pilosidad.Pec.. } \\
\text { Envés_1(Casi glabra) }\end{array}$ & $-4,099,795$ & 0.01171875 & 0.37109375 & 0.03291465 & 0.42493226 & $4.14 \mathrm{E}-05$ \\
\hline D.N.total & $-410,537$ & $112,109,375$ & $411,588,542$ & $119,640,345$ & $353,629,317$ & $4.04 \mathrm{E}-05$ \\
\hline Apice.Hoja_1(Aguda) & $-4,157,969$ & 0.0703125 & 0.2890625 & 0.07614683 & 0.25503555 & $3.21 \mathrm{E}-05$ \\
\hline Fruto.Largo.mm & $-4,257,802$ & $637,253,906$ & $70,724,349$ & 0.4734597 & 0.79685965 & $2.06 \mathrm{E}-05$ \\
\hline D.Cantidad.Basal & $-4,329,116$ & 0.8671875 & $249,088,542$ & 0.83205876 & $181,819,282$ & $1.50 \mathrm{E}-05$ \\
\hline $\begin{array}{l}\text { Margen.Hoja.Terc. } \\
\text { Sup_2 (Entero) }\end{array}$ & $-4,457,071$ & 0.03515625 & 0.23567708 & 0.0440212 & 0.2180941 & $8.31 \mathrm{E}-06$ \\
\hline $\begin{array}{l}\text { Pilosidad.Envés. } \\
\text { Nerv_1(Casi glabra) }\end{array}$ & $-4,468,037$ & 0 & 0.38932292 & 0 & 0.42240314 & $7.89 \mathrm{E}-06$ \\
\hline $\begin{array}{l}\text { D..Tipo_3(Bolsillos } \\
\text { cn pocos pelos) }\end{array}$ & $-4,500,464$ & 0 & 0.4453125 & 0 & 0.47966884 & $6.78 \mathrm{E}-06$ \\
\hline $\begin{array}{l}\text { D.Tamaño.Medios_3 } \\
\text { (Pequeños) }\end{array}$ & $-4,720,831$ & 0.10546875 & 0.4609375 & 0.16494369 & 0.3650202 & $2.35 \mathrm{E}-06$ \\
\hline $\begin{array}{l}\text { Pilosidad.Envés. } \\
\text { Lam_1(Casi glabra) }\end{array}$ & $-4,919,631$ & 0 & 0.46354167 & 0 & 0.45676222 & $8.67 \mathrm{E}-07$ \\
\hline $\begin{array}{l}\text { Lam.Cont.Haz. } \\
\text { Env_1 (Concolor) }\end{array}$ & $-5,279,107$ & 0.3125 & 0.76953125 & 0.46351241 & 0.41968107 & $1.30 \mathrm{E}-07$ \\
\hline $\begin{array}{l}\text { Pilosidad.Haz. } \\
\text { Nerv_1(Casi glabra) }\end{array}$ & $-5,361,218$ & 0.0234375 & 0.51171875 & 0.0658293 & 0.44150994 & $8.27 \mathrm{E}-08$ \\
\hline $\begin{array}{l}\text { Pilosidad.Haz. } \\
\text { Lam_1(Casi glabra) }\end{array}$ & $-558,363$ & 0.02734375 & 0.54557292 & 0.07318357 & 0.44992396 & $2.36 \mathrm{E}-08$ \\
\hline
\end{tabular}

